Marquette University

e-Publications@Marquette

Biological Sciences Faculty Research and

Publications

Biological Sciences, Department of

7-15-2018

\title{
Stress Promotes Drug Seeking Through Glucocorticoid- Dependent Endocannabinoid Mobilization in the Prelimbic Cortex
}

Jayme R. McReynolds

Marquette University, jayme.mcreynolds@marquette.edu

Elizabeth M. Doncheck

Marquette University

Yan Li

Medical College of Wisconsin

Oliver Vranjkovic

Marquette University, oliver.vranjkovic@marquette.edu

Evan N. Graf

Marquette University

See next page for additional authors

Follow this and additional works at: https://epublications.marquette.edu/bio_fac

Part of the Biology Commons

\section{Recommended Citation}

McReynolds, Jayme R.; Doncheck, Elizabeth M.; Li, Yan; Vranjkovic, Oliver; Graf, Evan N.; Ogasawara, Daisuke; Cravatt, Benjamin F.; Baker, David A.; Liu, Qing-Song; Hillard, Cecilia J.; and Mantsch, John R., "Stress Promotes Drug Seeking Through Glucocorticoid-Dependent Endocannabinoid Mobilization in the Prelimbic Cortex" (2018). Biological Sciences Faculty Research and Publications. 610.

https://epublications.marquette.edu/bio_fac/610 


\section{Authors}

Jayme R. McReynolds, Elizabeth M. Doncheck, Yan Li, Oliver Vranjkovic, Evan N. Graf, Daisuke Ogasawara, Benjamin F. Cravatt, David A. Baker, Qing-Song Liu, Cecilia J. Hillard, and John R. Mantsch 
Marquette University

e-Publications@Marquette

\section{Biomedical Science Faculty Research and Publications/College of Health Sciences}

This paper is NOT THE PUBLISHED VERSION; but the author's final, peer-reviewed manuscript. The published version may be accessed by following the link in th citation below.

Biological Psychiatry, Vol. 84, No. 2 (July 15, 2018): 85-94. DOI. This article is (C) Elsevier and permission has been granted for this version to appear in e-Publications@Marquette. Elsevier does not grant permission for this article to be further copied/distributed or hosted elsewhere without the express permission from Elsevier.

\section{Stress Promotes Drug Seeking Through Glucocorticoid-Dependent Endocannabinoid Mobilization in the Prelimbic Cortex}

Jayme R. McReynolds

Department of Biomedical Sciences, Marquette University, Milwaukee, Wisconsin Elizabeth M. Doncheck

Department of Biomedical Sciences, Marquette University, Milwaukee, Wisconsin Yan Li

Department of Pharmacology and Toxicology and Neuroscience Research Center, Medical College of Wisconsin, Milwaukee, Wisconsin

Oliver Vranjkovic

Department of Biomedical Sciences, Marquette University, Milwaukee, Wisconsin

Evan N. Graf

Department of Biomedical Sciences, Marquette University, Milwaukee, Wisconsin

Daisuke Ogasawara

Department of Chemical Physiology, Scripps Research Institute, La Jolla, California 


\section{Benjamin F. Cravatt}

Department of Chemical Physiology, Scripps Research Institute, La Jolla, California

\section{David A. Baker}

Department of Biomedical Sciences, Marquette University, Milwaukee, Wisconsin

\section{Qing-Song Liu}

Department of Pharmacology and Toxicology and Neuroscience Research Center, Medical College of Wisconsin, Milwaukee, Wisconsin

\section{Cecilia J. Hillard}

Department of Pharmacology and Toxicology and Neuroscience Research Center, Medical College of Wisconsin, Milwaukee, Wisconsin

\section{John R. Mantsch}

Department of Biomedical Sciences, Marquette University, Milwaukee, Wisconsin

\section{Abstract}

\section{Background}

Clinical reports suggest that rather than directly driving cocaine use, stress may create a biological context within which other triggers for drug use become more potent. We hypothesize that stress-induced increases in corticosterone "set the stage" for relapse by promoting endocannabinoid-induced attenuation of inhibitory transmission in the prelimbic cortex $(\mathrm{PL})$.

\section{Methods}

We have established a rat model for these stage-setting effects of stress. In this model, neither a stressor (electric footshock) nor stress-level corticosterone treatment alone reinstates cocaine seeking following selfadministration and extinction, but each treatment potentiates reinstatement in response to an otherwise subthreshold cocaine priming dose $(2.5 \mathrm{mg} / \mathrm{kg}$, intraperitoneal). The contributions of endocannabinoid signaling in the PL to the effects of stress-level corticosterone on PL neurotransmission and cocaine seeking were determined using intra-PL microinfusions. Endocannabinoid-dependent effects of corticosterone on inhibitory synaptic transmission in the rat PL were determined using whole-cell recordings in layer $\mathrm{V}$ pyramidal neurons.

\section{Results}

Corticosterone application attenuated inhibitory synaptic transmission in the PL via cannabinoid receptor type 1 $\left(\mathrm{CB}_{1} \mathrm{R}\right)$ - and 2-arachidonoylglycerol-dependent inhibition of gamma-aminobutyric acid release without altering postsynaptic responses. The ability of systemic stress-level corticosterone treatment to potentiate cocaineprimed reinstatement was recapitulated by intra-PL injection of corticosterone, the $\mathrm{CB}_{1} \mathrm{R}$ agonist WIN 55,212-2, or the monoacylglycerol lipase inhibitor URB602. Corticosterone effects on reinstatement were attenuated by intra-PL injections of either the $\mathrm{CB}_{1} \mathrm{R}$ antagonist, $\underline{\mathrm{AM} 251}$, or the diacylglycerol lipase inhibitor, DO34.

\section{Conclusions}

These findings suggest that stress-induced increases in corticosterone promote cocaine seeking by mobilizing $\underline{2-}$ arachidonoylglycerol in the $\mathrm{PL}$, resulting in $\mathrm{CB}_{1} \mathrm{R}$-mediated attenuation of inhibitory transmission in this brain region. 


\section{Keywords}

Addiction, Cocaine, Corticosterone, Endocannabinoids, Prelimbic cortex, Self-administration

Despite efforts to identify effective treatment strategies for patients with substance use disorders (SUDs), relapse rates remain high. This prevalence is due in part to the complex interactions among factors that promote drug craving and seeking. One factor, stress, is particularly problematic, as it is prevalent in SUD populations and unavoidable in daily life. Although there is a well-demonstrated influence of stress on drug craving in individuals with SUDs $\underline{1}, \underline{2}$, the effects of stress on drug-seeking behavior can be complex. Emerging evidence indicates that stress does not always directly trigger craving but instead can increase reactivity to other relapse-inducing stimuli $\underline{3}, \underline{4} \underline{5}, \underline{6}$. This understudied influence of stress can also be observed in rats $\underline{7} \underline{8}, \underline{9} \underline{10}$. While it has been established that both stress (11) and high-dose priming injections of the drug (12) can trigger reinstatement, under conditions in which stress does not directly trigger reinstatement it can potentiate cocaine seeking in response to an otherwise subthreshold priming injection of cocaine following self-administration and extinction $\underline{8}, \underline{10}$.

Footshock-induced potentiation of cocaine seeking is glucocorticoiddependent, and corticosterone administration at a dose that reproduces stress-induced levels is sufficient to potentiate reinstatement (8). A likely site of corticosterone regulation of cocaine use is the medial prefrontal cortex. The prelimbic region of the medial prefrontal cortex has been extensively implicated in cocaine-seeking behavior $\underline{13}, \underline{14}, \underline{15}$ and is highly regulated by stress and glucocorticoids $\underline{16}, \underline{17}$. Taken together, these data provide strong evidence that the prefrontal cortex is a key site for corticosterone actions that mediate stress regulation of cocaine-seeking behavior.

Corticosterone may regulate prefrontal cortical function through interactions with the endocannabinoid system. In the prefrontal cortex, cannabinoid receptor type $1\left(\mathrm{CB}_{1} \mathrm{R}\right)$ is predominantly located on perisomatically targeting gamma-aminobutyric acidergic (GABAergic) interneurons (18), positioning activation of this system to regulate output of prefrontal pyramidal neurons. In mice, stress can increase levels of the endocannabinoid 2arachidonoylglycerol(2-AG) in the prefrontal cortex in a glucocorticoid-dependent manner (18). Furthermore, bath application of corticosterone to mouse prefrontal slices attenuates inhibitory neurotransmission in a $\mathrm{CB}_{1} \mathrm{R}-$ dependent manner (18). Importantly, the same stressor, electric footshock, which potentiates reinstatement of cocaine seeking, also elevates levels of endocannabinoids in subregions of the prefrontal cortex in drug-naïve rats $(10)$. Taken together, these data suggest that stress, and corticosterone, potentiate reinstatement through increased $\mathrm{CB}_{1} \mathrm{R}$ activation in the prelimbic cortex $(\mathrm{PL})$. Importantly, we and others have demonstrated that systemic $\mathrm{CB}_{1} \mathrm{R}$ antagonism blocks stress-potentiated but not stress-induced $\underline{19}, \underline{20}$ or cocaineinduced $\underline{10}$, 20reinstatement.

In the current study, we test the hypothesis that in rats, corticosterone exerts effects in the prelimbic subregion of the medial prefrontal cortex to potentiate reinstatement of cocaine seeking through a $C_{1} R$-dependent attenuation of inhibitory neurotransmission. We demonstrate that corticosterone acts in the PL to potentiate cocaine seeking, and that corticosterone attenuates inhibitory neurotransmission in PL slices in a $\mathrm{CB}_{1} \mathrm{R}$ dependent manner. Furthermore, we show that $\mathrm{CB}_{1} \mathrm{R}$ activation in the $\mathrm{PL}$ is necessary for stress- and corticosterone-potentiated reinstatement as well as sufficient to reproduce the potentiating effects of stress or corticosterone administration. Finally, we determine that $P L C B_{1} R$ activation involves 2-AG signaling, as inhibition of 2-AG production blocks and attenuation of 2-AG breakdown reproduces corticosterone-potentiated reinstatement. 


\section{Methods and Materials}

\section{Subjects}

A total of 102 male Sprague Dawley rats (275 to $300 \mathrm{~g}$ at arrival; Envigo RMS, Inc., Indianapolis, IN), were individually housed in a 12-hour reverse light/dark cycle ( $7 \mathrm{am}$ to $7 \mathrm{pm}$ lights off) as described in the Supplement. All behavioral procedures were conducted in the dark phase. Of the rats designated for behavioral testing, 14 were excluded from the study because of misplaced cannulation or because they did not complete all behavioral testing.

\section{Surgery}

For intravenous self-administration and reinstatement testing, rats were anesthetized with ketamine $\mathrm{HCl}(100$ $\mathrm{mg} / \mathrm{kg}$, intraperitoneal [i.p.]; Henry Schein, Melville, NY) and xylazine (2 mg/kg, i.p.; Henry Schein) and surgically implanted with indwelling venous catheters. Rats that received intracranial microinfusions before reinstatement testing also had a bilateral guide cannulatargeting the PL. All procedures are described in detail in the Supplement.

\section{Cocaine Self-administration, Extinction, and Reinstatement}

Rats were trained to press a lever to self-administer cocaine $(0.5 \mathrm{mg} / \mathrm{kg} /$ infusion $)$ under a fixed-ratio 4 schedule of reinforcement during daily 2-hour sessions. Once trained, rats underwent daily self-administration for 14 days before extinction training, during which the cocaine solution was replaced with saline. Each rat underwent extinction training until extinction criterion was met ( $<10$ lever presses/ 2 hours) at which point reinstatement testing was conducted. Procedures are described in detail in the Supplement.

\section{Reinstatement Conditions}

The 2-hour reinstatement sessions were preceded by footshock, corticosteroneadministration, and/or drug delivery, as described in the Results, and were otherwise identical to extinction conditions. A within-subject testing design was utilized in which each rat received all treatments in a given experiment in a counterbalanced order. Nine rats did not complete all tests and were excluded from the study. Reinstatement was defined as significantly increased responding on the lever previously reinforced by cocaine relative to the preceding extinction session and compared with control conditions. Responding on a second lever that was inactive through self-administration training was also recorded during the sessions. There were no significant changes in inactive lever responding between extinction and reinstatement testing days (Supplemental Figure S3). Potentiated cocaine seeking was defined as significant reinstatement in response to low-dose cocaine (2.5 $\mathrm{mg} / \mathrm{kg}$, i.p.) following shock or drug pretreatment under conditions where neither low-dose cocaine nor the drug pretreatment alone produced reinstatement.

\section{Intracranial Drug Administration}

Intra-PL infusions were given at various time points before reinstatement testing as described in the Results. All infusions were a volume of $0.3 \mu \mathrm{L}$ at a rate of $0.3 \mu \mathrm{L} / \mathrm{min}$. Placement of the guide cannula was verified as described in the Supplement. Albeit in only 5 rats, injections outside of the PL did not have effects on cocaineseeking behavior.

\section{Slice Electrophysiology}

Whole-cell voltage clamp recordings were made from pyramidal neurons in layer $\mathrm{V}$ of the PL of drug-naïve rats as described in detail in the Supplement. For recording of evoked inhibitory postsynaptic currents (IPSCs), layer $\checkmark$ pyramidal neurons were voltage-clamped at $-60 \mathrm{mV}$, and IPSCs were evoked at $0.05 \mathrm{~Hz}$ by a tungsten stimulation electrode placed near the apical dendrites. Spontaneous miniature IPSCs (mIPSCs) were recorded from the pyramidal neurons at a holding potential of $-70 \mathrm{mV}$. Action potential generation was blocked 
with tetrodotoxin $(0.5 \mu \mathrm{M})$. Glutamate receptor antagonists 6-cyano-7-nitroquinoxaline-2,3-dione $(10 \mu \mathrm{M})$ and D-2-amino-5-phosphonovaleric acid $(20 \mu \mathrm{M})$ were present in the artificial cerebrospinal fluid throughout the experiments. Series resistance ( 15 to $30 \mathrm{M} \Omega$ ) was monitored throughout the recordings, and data were discarded if the resistance changed by more than $20 \%$. All recordings were performed at $32 \pm 1^{\circ} \mathrm{C}$.

\section{Mass Spectrometry}

To determine if the diacylglycerol lipase (DAGL) inhibitor DO34 attenuates corticosterone-induced 2-AG levels, rats received intra-PL infusions of DO34 $(1 \mu \mathrm{g} / 0.3 \mu \mathrm{L}$ ) or vehicle (70\% dimethyl sulfoxide) 30 minutes before a corticosterone ( $2 \mathrm{mg} / \mathrm{kg}$, i.p.) or vehicle (10\% ethanol) injection. Rats were rapidly decapitated 45 minutes following the injection and brains were removed within 90 seconds, frozen in liquid nitrogen, and stored at $-80^{\circ} \mathrm{C}$. The $\mathrm{PL}$ was dissected and endocannabinoids extracted as previously described (10). $\mathrm{N}$ arachidonoylethanolamine and 2-AG were isolated and quantified as described in the Supplement using isotope dilution and liquid chromatography/mass spectrometry.

\section{Statistical Analysis}

Statistical analyses were conducted using one- or two-way repeated-measures (RM) analysis of variance (ANOVA), followed by Bonferroni post hoc tests when appropriate for behavioral and mass spectrometry experiments and Student's ttest for electrophysiology experiments (see the Supplement for more detail).

\section{Results}

\section{Corticosterone Acts in the PL to Potentiate Reinstatement}

After 14 days of stable cocaine self-administration, responding was extinguished and rats were tested for reinstatement of cocaine seeking. All self-administration and extinction data are displayed in Supplemental

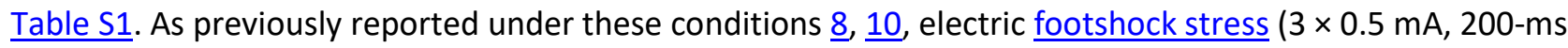
duration, mean intershock interval 40 seconds, range 10 to 70 seconds over a 15-minute period) alone did not induce reinstatement, but rather potentiated cocaine seeking in response to an otherwise subthreshold priming dose of cocaine $(2.5 \mathrm{mg} / \mathrm{kg}$, i.p.; Figure 1A; two-way RM ANOVA, reinstatement condition $\times$ day interaction $\left[F_{3,15}=17.11, p<.001\right]$, post hoc comparison, shock/cocaine combination vs. extinction, $\left.p<.05\right)$. The ability of footshock to potentiate reinstatement was reproduced by systemic administration of corticosterone $(2 \mathrm{mg} / \mathrm{kg}$, i.p.) at a dose that established footshock-induced levels of plasma corticosterone (Supplemental Figure S1). As with footshock, corticosterone alone was insufficient to induce reinstatement. However, when corticosterone was combined with an otherwise subthreshold priming injection of cocaine, significant reinstatement was observed (Figure 1B; two-way RM ANOVA, reinstatement condition $\times$ day $\left[F_{3,12}=10.30, p<.001\right]$, post hoc comparison, corticosterone/cocaine combination vs. extinction, $p<.05)$. To localize corticosterone action in the brain, soluble 2-hydroxypropyl- $\beta$-cyclodextrin-conjugated corticosterone ( $50 \mathrm{ng} / 0.3 \mu \mathrm{L}$ ), was microinfused directly into the PL 10 minutes before low-dose cocaine. As was the case with systemic administration, intra-PL administration of corticosterone alone did not increase cocaine seeking, but rather induced significant reinstatement when given before administration of the subthreshold priming dose of cocaine (Figure 1C; twoway RM ANOVA, reinstatement condition $\times$ day interaction $\left[F_{2,12}=4.89, p<.05\right]$, post hoc comparison, corticosterone/cocaine combination vs. extinction, $p<.05)$. These findings identify the PL as an important site for corticosterone effects on cocaine seeking. 

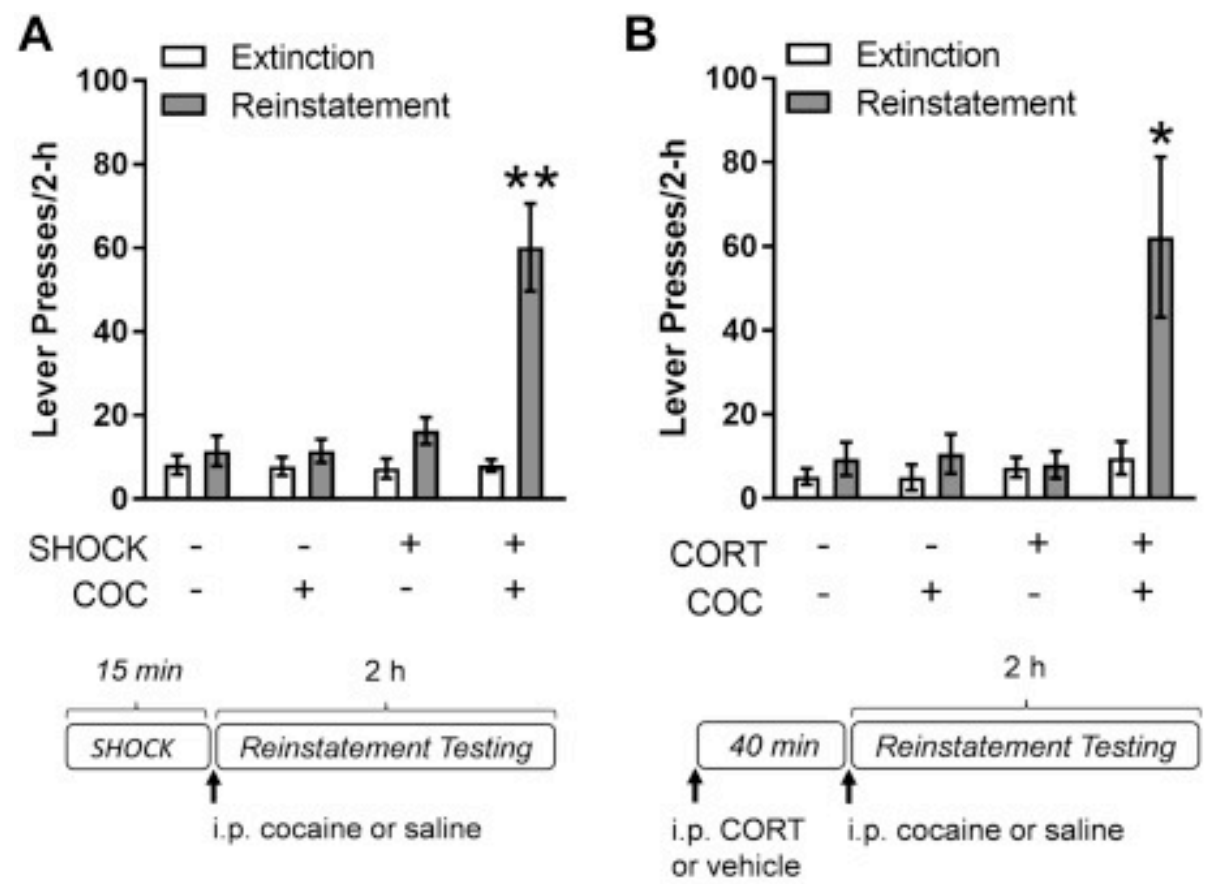

\section{C}
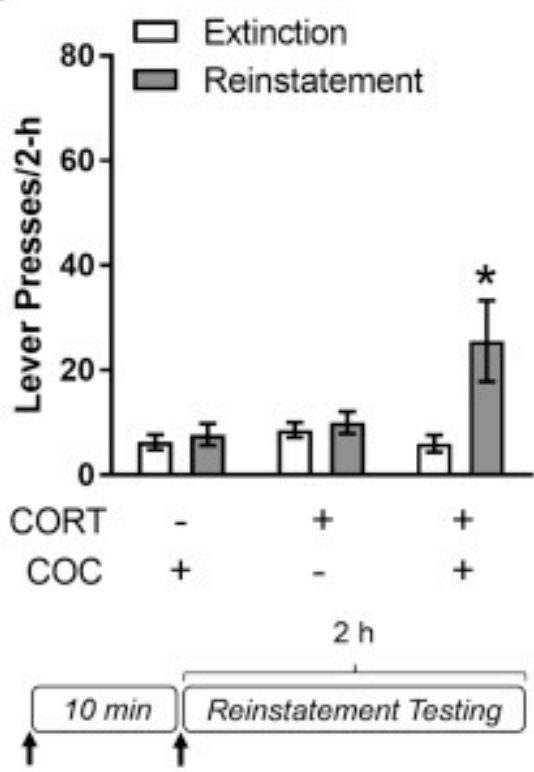

PL CORT i.p. cocaine or saline
D

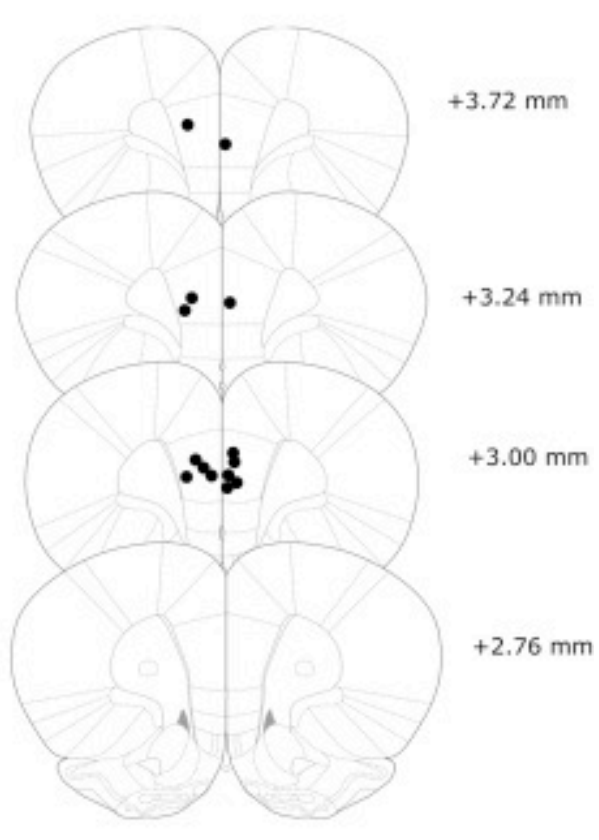

or vehicle

Figure 1. Corticosterone (CORT) acts in the prelimbic cortex to potentiate reinstatement of cocaine (COC) seeking. (A) Electric footshock stress (SHOCK) $(n=6)$ potentiates reinstatement when given in combination with a low dose of cocaine (COC) $(2.5 \mathrm{mg} / \mathrm{kg}$, intraperitoneal [i.p.]). (B) Systemic corticosterone ( $2 \mathrm{mg} / \mathrm{kg}$, i.p.; $n=5)$ reproduces the effect of footshock and potentiates reinstatement when given 40 minutes before an injection of low-dose cocaine (2.5 $\mathrm{mg} / \mathrm{kg}$, i.p.). (C) 2-Hydroxypropyl- $\beta$-cyclodextrin (HBC)-conjugated corticosterone (50 ng/0.3 $\mu \mathrm{L} ; n=7)$ administered directly into the prelimbic cortex (PL) 10 minutes before a low-dose cocaine injection $(2.5 \mathrm{mg} / \mathrm{kg}$, i.p.) induces significant reinstatement whereas either administered alone does not $\left(p<.05 ;{ }^{*} p<.01,{ }^{*} p<.05\right.$, compared with extinction). (D) Injection needle tips of all rats included in the intra-PL corticosterone experiment. Data are presented as mean $\pm \underline{\text { SEM}}$. 


\section{Corticosterone Attenuates PL Inhibitory Neurotransmission in a $\mathrm{CB}_{1} \mathrm{R}$-Dependent}

\section{Manner}

To investigate corticosterone effects on PL neurotransmission in rats, whole-cell recordings were made in visually identified layer $\mathrm{V}$ pyramidal neurons in rat PL. We initially examined the effects of corticosterone on evoked IPSCs. Following stable baseline recordings, bath application of corticosterone $(1 \mu \mathrm{M})$ for 30 minutes gradually decreased the amplitude of evoked IPSCs with the depression having a rapid onset ( $\sim 5$ minutes) and peaking in 30 minutes (Figure 2A). This depression was accompanied by an increase in the paired-pulse ratio, suggesting a presynaptic mechanism (Figure 2B). The depression of evoked IPSC amplitude by corticosterone was prevented by the continuous presence of $C_{1} R$ antagonist $A M 251$ ( $2 \mu \mathrm{M}$; Figure 2A). Moreover, in the presence of $A M 251$, paired-pulse ratio was not altered by corticosterone (Figure $2 B$ ). Thus, these results suggest that corticosterone depresses IPSCs in rat PL through a presynaptic $\mathrm{CB}_{1} \mathrm{R}$-dependent mechanism. To further test this, we examined the effects of corticosterone on mIPSCs in layer $V$ pyramidal neurons in rat PL slices. A change in mIPSC frequency indicates a presynaptic mechanism, whereas a change in mIPSC amplitude signifies a likely change in postsynaptic responsiveness (21). PL slices were perfused with either vehicle or corticosterone $(1 \mu \mathrm{M})$ for 20 to 60 minutes, and mIPSCs were recorded from layer $V$ pyramidal neurons. Corticosterone perfusion significantly decreased the frequency of mIPSCs (igure 2D) as shown by both a decrease in the mean frequency of mIPSCs $(p<.01)$ and a rightward shift in the cumulative probability plot for interevent intervals. By contrast, corticosterone did not alter the mean amplitude of mIPSCs (Figure 2E; $p>.05$ ) or the cumulative amplitude distribution ( $p>$.05). To investigate if corticosterone depressed mIPSCs through a $\mathrm{CB}_{1} \mathrm{R}$-dependent mechanism, we repeated the above experiments in the presence of the $C_{1} R$ antagonist $A M 251$. PL slices were perfused with either AM251 (2 $\mu \mathrm{M})$ alone or AM251 with corticosterone $(1 \mu \mathrm{M})$ for 20 to 60 minutes. In the presence of AM251, corticosterone did not significantly alter mIPSCs (igire 2D; $p>05$ ) as there were no significant changes in the mean frequency of mIPSCs $(p>.05)$ or the cumulative interevent interval probability plot $(p>.05)$. In the presence of AM251, corticosterone did not significantly alter the mean amplitude of mIPSCs (Figure $2 \mathrm{E} ; p>.05$ ) or cumulative amplitude distribution $(p>.05)$. These results suggest that corticosterone-induced depression of mIPSCs in the PL is dependent on presynaptic $\mathrm{CB}_{1} \mathrm{R}$-mediated suppression of $\mathrm{GABAergic}$ transmission.

A

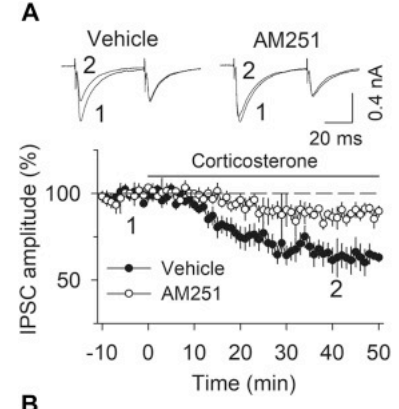

B

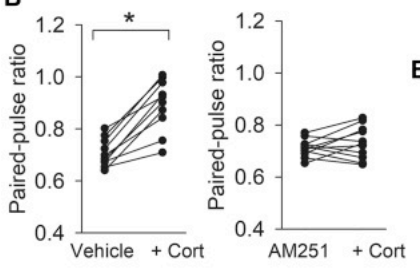

C

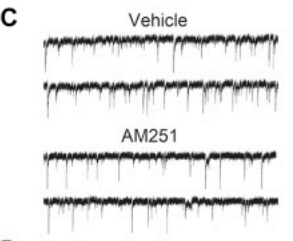

D
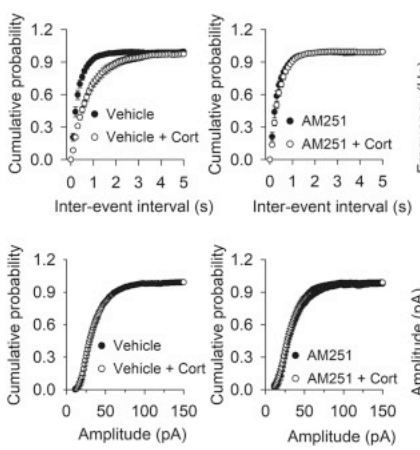

Vehicle + Cort

$\mathrm{AM} 251+$ Cort
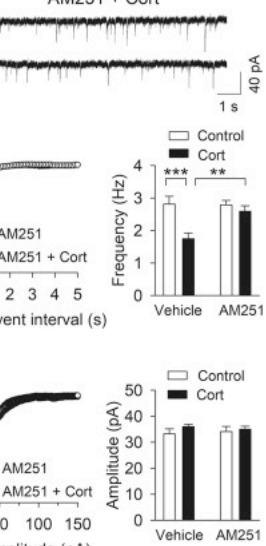

Figure 2. Corticosterone (Cort) depressed evoked and miniature inhibitory postsynaptic currents (mIPSCs) through a cannabinoid receptor type $1\left(\mathrm{CB}_{1} \mathrm{R}\right)$-dependent mechanism in rat prelimbic cortex (PL) slices. (A) Bath application of corticosterone $(1 \mu \mathrm{M})$ caused rapid depression of evoked IPSCs ( $n=10$ neurons; $n=2-3$ rats) in layer $V$ pyramidal neurons in the prelimbic cortex (PL), which were blocked by the $\mathrm{CB}_{1} \mathrm{R}$ antagonist $\mathrm{AM} 251$ ( $2 \mu \mathrm{M}, n=11$ neurons; $n=2-3$ rats). (B) Bath application of corticosterone increased the paired-pulse ratio, which was blocked by AM251 ( $n=11$ neurons; $n=2-3$ rats, $p$ $<.05)$. (C) Representative traces of mIPSCs recorded in layer V pyramidal neurons in PL slices that were treated with vehicle (control), corticosterone $(1 \mu \mathrm{M}), \mathrm{AM} 251(2 \mu \mathrm{M})$, or AM251 plus corticosterone $(1 \mu \mathrm{M})$. (D) Corticosterone treatment 
decreased the mean frequency of mIPSCs ( $n=9-11$ neurons; $n=2-3$ rats, $p<.01)$ and caused a right shift of the interevent intervals of the cumulative probability plot. However, in the presence of AM251, corticosterone did not alter the mean frequency of mIPSCs ( $n=10-11$ neurons; $n=2-3$ rats, $p>.05$ ) or interevent intervals of the cumulative probability plot. (E) Corticosterone did not alter the mean amplitude of mIPSCs $(p>.05)$ and cumulative amplitude distribution. In addition, in the presence of AM251, corticosterone had no significant effect on the mean amplitude of mIPSCs $(p>.05)$ or on the cumulative amplitude distribution of mIPSCs.

\section{$\mathrm{CB}_{1} \mathrm{R}$ Activation in the PL Is Necessary and Sufficient for Stress- and Corticosterone- Potentiated Reinstatement}

We have previously shown that stress-potentiated reinstatement is prevented by systemic administration of the $\mathrm{CB}_{1} \mathrm{R}$ antagonist, $\mathrm{AM} 251(10)$. These data, in combination with the observed $\mathrm{CB}_{1} \mathrm{R}$-dependent corticosterone attenuation of PL inhibitory neurotransmission, led us to hypothesize that stress-potentiated reinstatement is mediated by corticosterone-regulated endocannabinoidsignaling and $\mathrm{PLCB} \mathrm{CB}_{1} \mathrm{R}$ activation. Consistent with this possibility, intra-PL administration of AM251 (300 ng/0.3 $\mu \mathrm{L}) 15$ minutes before footshock blocked stresspotentiated reinstatement (Figure 3A; two-way RM ANOVA, reinstatement condition $\times$ day interaction $\left[F_{3,15}=\right.$ $15.71, p<.001$ ]; post hoc comparison, vehicle/shock/cocaine combination vs. extinction, $p<.05$; AM251/shock/cocaine combination vs. extinction, $p>.05)$. Moreover, intra-PL administration of AM251 (300 $\mathrm{ng} / 0.3 \mu \mathrm{L}) 15$ minutes before systemic corticosterone administration $(2 \mathrm{mg} / \mathrm{kg}$, i.p.) also blocked corticosteronepotentiated reinstatement ( $\underline{\text { Figure } 3 \mathrm{~B}}$; two-way RM ANOVA, reinstatement condition $\times$ day interaction $\left[F_{3,15}=\right.$ $6.94, p<.01$ ], post hoc comparison, vehicle/corticosterone/cocaine combination vs. extinction, $p<.05$; AM251/corticosterone/cocaine combination vs. extinction, $p>.05$ ). These data provide compelling evidence that stress, likely through corticosterone, promotes cocaine seeking via increased endocannabinoid signaling in the $\mathrm{PL}$. To determine if $\mathrm{CB}_{1} R$ activation in the $\mathrm{PL}$ is sufficient to potentiate cocaine-primed reinstatement, we tested rats for the effects of the intra-PL delivery of the $\mathrm{CB}_{1} \mathrm{R}$ agonist WIN 55,212-2 on reinstatement. Neither intra-PL WIN 55,212-2 (50 ng/0.3 $\mu \mathrm{L} ; 15$-minute pretreatment) nor $2.5 \mathrm{mg} / \mathrm{kg}$ (i.p.) cocaine alone increased cocaine seeking. However, when intra-PL WIN 55,212-2 preceded the cocaine injection, significant reinstatement was observed (Figure 4A; two-way RM ANOVA, reinstatement condition $\times$ day interaction $\left[F_{2,10}=\right.$ $7.09, p<.05]$, post hoc comparison WIN/cocaine combination vs. extinction, $p<.05$ ).
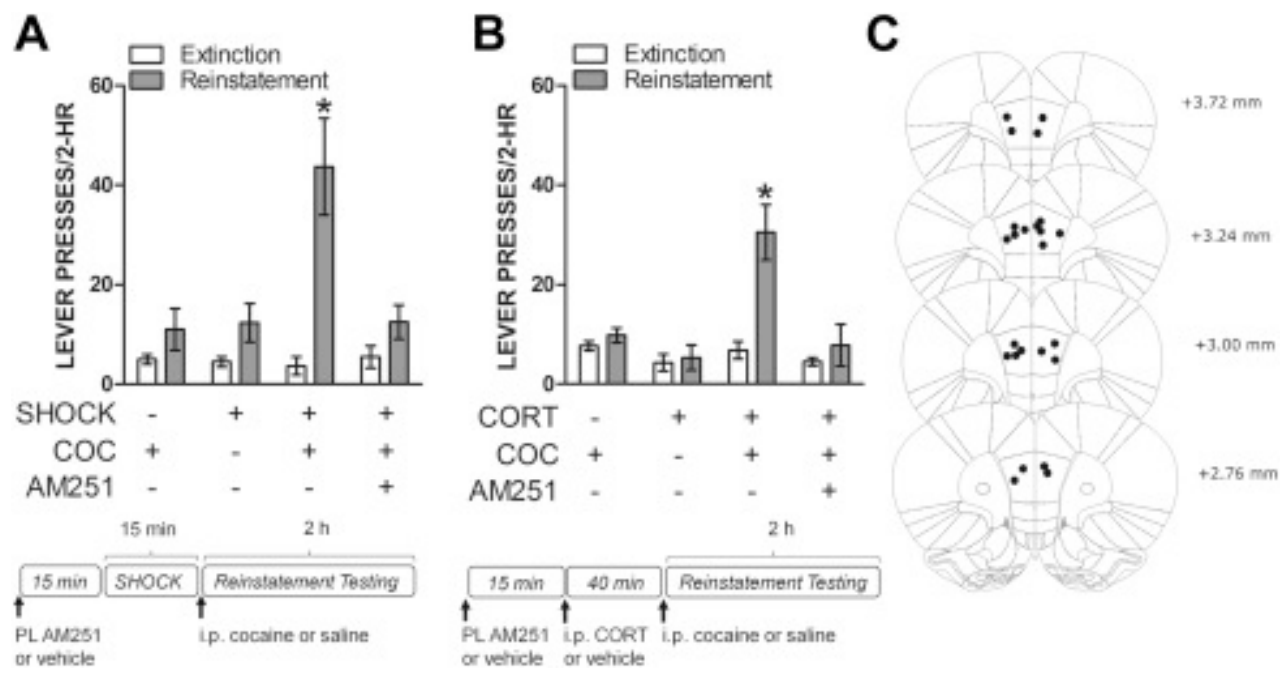

Figure 3. Stress- and corticosterone-potentiated reinstatement is blocked by cannabinoid receptor type $1\left(\mathrm{CB}_{1} \mathrm{R}\right)$ antagonism in the prelimbic cortex (PL). (A)Electric footshock stress (SHOCK)-potentiated reinstatement to lowdosecocaine (COC) $\left(2.5 \mathrm{mg} / \mathrm{kg}\right.$, intraperitoneal [i.p.]) is blocked by pretreatment with an intra-PL infusion of the $\mathrm{CB}_{1} R$ antagonist AM251 (300 ng/0.3 $\mathrm{LL}) 15$ minutes before the reinstatement test $\left(n=6,{ }^{*} p<.05\right.$, compared with extinction). (B)Corticosterone (CORT) ( $2 \mathrm{mg} / \mathrm{kg}$, i.p.)-potentiated reinstatement to low-dose cocaine is blocked by pretreatment with an intra-PL infusion of AM251 15 minutes before the reinstatement test $(n=6, * p<.05$, compared with 
extinction). (C) Injection needle tips of all rats included in the intra-PL AM251 experiment. Data are presented as mean $\pm \underline{\text { SEM. }}$.
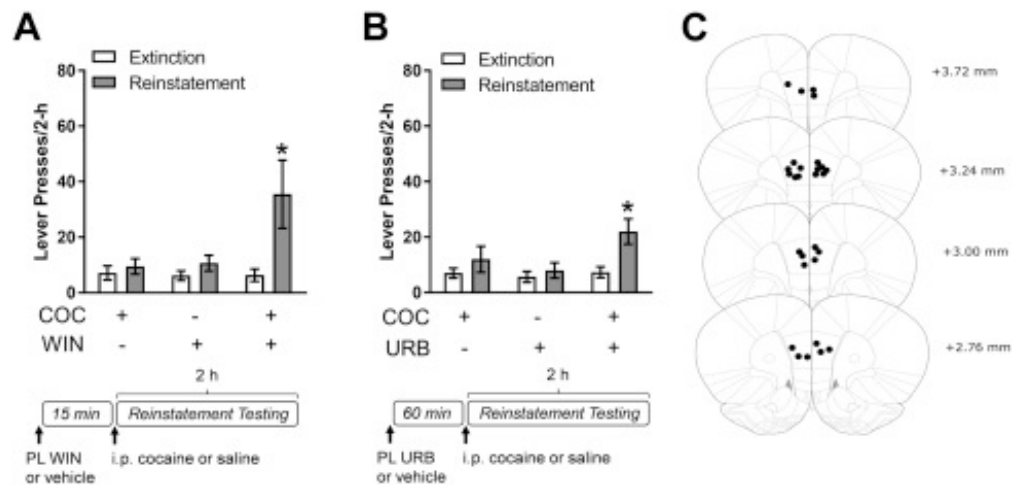

Figure 4. Cannabinoid receptor type $1\left(\mathrm{CB}_{1} \mathrm{R}\right)$ activation in the prelimbic cortex $(\mathrm{PL})$ is sufficient to potentiate reinstatement. (A) Intra-PL administration of the $\mathrm{CB}_{1} \mathrm{R}$ agonist WIN 55,212-2 (WIN) (50 ng/0.3 $\mu \mathrm{L}$ ) 15 minutes before a lowdosecocaine injection (COC) $(2.5 \mathrm{mg} / \mathrm{kg}$, intraperitoneal [i.p.]) induces significant reinstatement of cocaine-seeking behavior while either administered alone does not $\left(n=6,{ }^{*} p<.05\right.$, compared with extinction). (B) Intra-PL administration of a monoacylglycerol lipase inhibitor URB602 (URB) (300 pmol/0.3 $\mu \mathrm{L}$ ), which elevates 2-arachidonoylglycerol levels and acts an indirect agonist of $\mathrm{CB}_{1} \mathrm{R}, 60$ minutes before a low-dose cocaine injection $(2.5 \mathrm{mg} / \mathrm{kg}$, i.p.) induces significant reinstatement while administration of either alone does not ( $n=6,{ }^{*} p<.05$, compared with extinction). (C) Injection needle tips of all rats included in the intra-PL experiment. Data are presented as mean $\pm \underline{\mathrm{SEM}}$.

There is evidence that stress can mobilize the endocannabinoid 2-AG in the PL (16), suggesting that $C_{1} B_{1}$ dependent effects of corticosterone may be mediated through 2-AG signaling. To determine if elevated 2-AG levels are sufficient to potentiate reinstatement, we tested rats for the effect of intra-PL administration of URB602, an inhibitor of the enzyme monoacylglycerol lipase, which is responsible for the breakdown of 2-AG. As was the case with corticosterone and WIN 55,212-2, neither intra-PL URB602 (300 pmol/0.3 $\mu \mathrm{L}$; 60-minute pretreatment) nor $2.5 \mathrm{mg} / \mathrm{kg}$ (i.p.) cocaine alone increased cocaine seeking, but significant reinstatement was observed when URB602 preceded the cocaine injection (Figure 4B; two-way RM ANOVA, reinstatement condition $\times$ day interaction $\left[F_{2,10}=5.89, p<.05\right]$, post hoc comparison URB602/cocaine combination vs. extinction, $p<.05)$. Collectively, these data demonstrate that endocannabinoid signaling in the PL is necessary and sufficient for stress- and corticosterone-potentiated reinstatement, and suggest that corticosterone may potentiate reinstatement through increased 2-AG signaling.

Corticosterone Potentiates Reinstatement Through Increased 2-AG Signaling in the PL To further test if PL 2-AG signaling mediates corticosterone effects on reinstatement, DO34 (provided by the Cravatt lab, Scripps Research Institute, La Jolla, CA), a novel inhibitor of DAGL, the synthetic enzyme for 2-AG, was used. Bath application of DO34 $(1 \mu \mathrm{M})$ to PL cortical slices blocked depolarization-induced suppression of inhibition ( $n=7$ to $8, p<.01$ ), which is $\mathrm{CB}_{1} \mathrm{R}$ dependent (18), suggesting that 2-AG signaling plays a critical role in endocannabinoid effects on PL neurotransmission (Figure 5A). Furthermore, intra-PL administration of DO34 (1 $\mu \mathrm{g} / 0.3 \mu \mathrm{L}$; 30 -minute pretreatment) before a systemic injection of corticosterone ( $2 \mathrm{mg} / \mathrm{kg}$, i.p.) significantly reduced PL 2-AG content in a corticosterone-dependent manner (Figure 5B; two-way ANOVA with DO34 and corticosterone treatments as between factors, main effect of DO34 $\left[F_{1,26}=6.97, p<.01\right]$, main effect of corticosterone $\left[F_{1,26}=1.98, p>.05\right]$, DO34 $\times$ corticosterone $\left.\left[F_{1,26}=2.09, p>.05\right]\right)$, while having no effect on levels of anandamide (Supplemental Figure S2; $p>.05$ ). Confirming a role for PL 2-AG in the corticosteronedependent stress-induced potentiation of cocaine seeking, intra-PL administration of DO34 (0.1, $1 \mu \mathrm{g} / 0.3 \mu \mathrm{L} ; 30$ minute pretreatment) before systemic corticosterone dose-dependently inhibited the ability of stress-level corticosterone to potentiate cocaine seeking when combined with low-dose cocaine (Figure 5C; two-way RM 
ANOVA, reinstatement condition $\times$ day interaction $\left[F_{4,16}=3.84, p<.05\right]$, post hoc comparisons, vehicle/corticosterone/cocaine combination vs. extinction, $p<.05$; DO34 0.1/corticosterone/cocaine or DO34 1.0/corticosterone/cocaine vs. extinction, $p>.05$ ). Taken together these data suggest that, during stress, corticosterone-induced PL 2-AG signaling acting via $\mathrm{CB}_{1} \mathrm{Rs}$ attenuates inhibitory neurotransmission to increase the excitability of cortical outputs mediating cocaine seeking, thereby promoting relapse vulnerability to ordinarily subthreshold triggers.
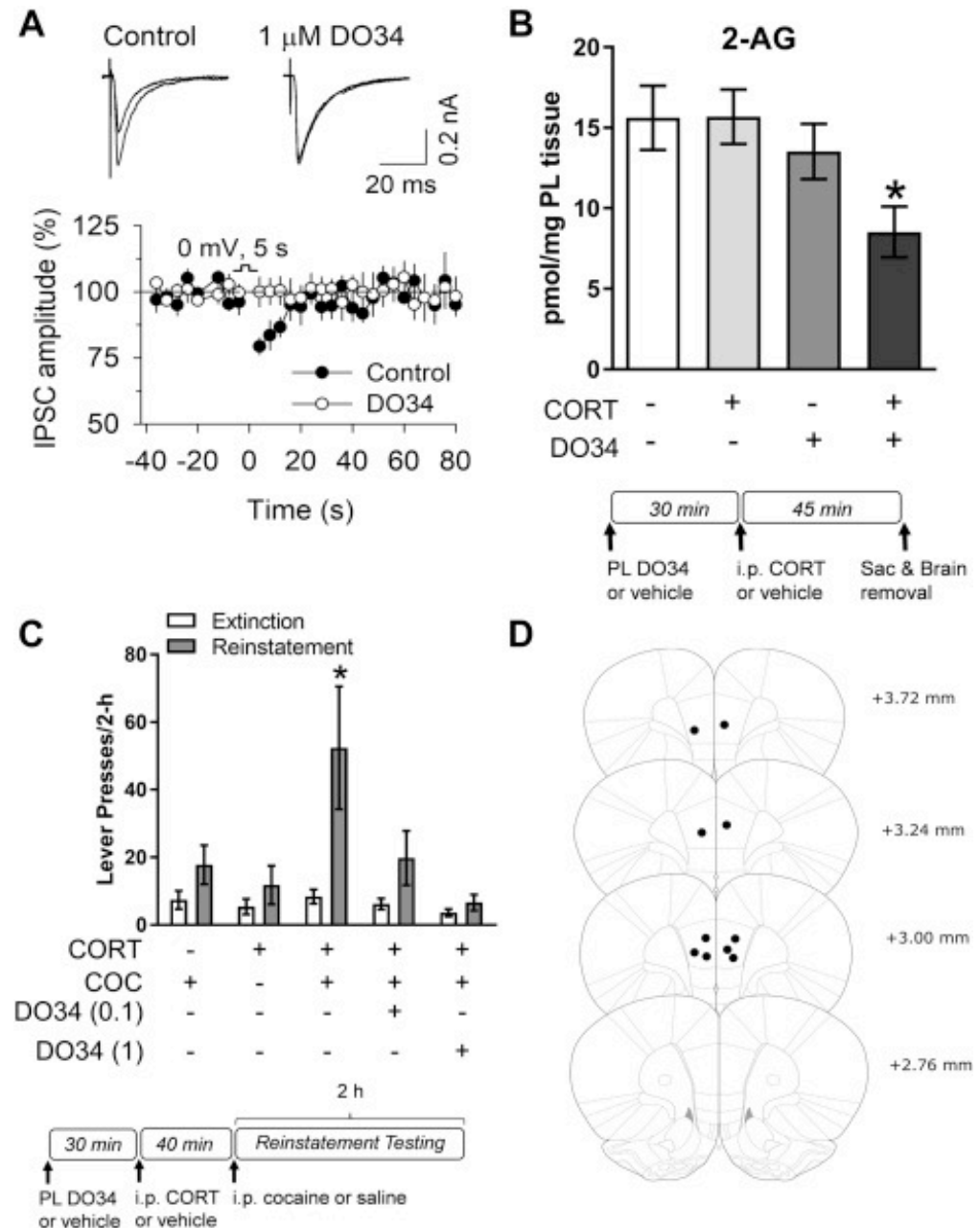

Figure 5. Corticosterone (CORT)-potentiated reinstatement is dependent on 2-arachidonoylglycerol (2-AG) signaling in the prelimbic cortex (PL). (A) Bath application of the diacylglycerol lipase inhibitor DO34 (1 $\mu \mathrm{M})$ to PL slices blocks depolarization-induced suppression of inhibition $(n=7-8, p<.01)$. (B) Direct administration of the diacylglycerol lipase inhibitor DO34 $(1 \mu \mathrm{g} / 0.3 \mu \mathrm{L})$ into the PL 30 minutes before a systemic injection of corticosterone $(2 \mathrm{mg} / \mathrm{kg}$, intraperitoneal [i.p.]) attenuates PL 2-AG in the presence of corticosterone $\left(n=7-8 ;{ }^{*} p<.05\right.$, main effect of DO34). (C) Corticosterone-potentiated reinstatement is dose-dependently blocked by intra-PL administration of DO34 (0.1 $\mu \mathrm{g} / 0.3 \mu \mathrm{L}, 1.0 \mu \mathrm{g} / 0.3 \mu \mathrm{L}) 30$ minutes before the corticosterone injection $\left(n=5 ;{ }^{*} p<.05\right.$, compared with extinction). (D) Injection needle tips of all rats included in the intra-PL experiment. Data are presented as mean $\pm \underline{\text { SEM}}$. COC, cocaine injection; IPSC, inhibitory postsynaptic currents; Sac, sacrifice animal.

\section{Discussion}

Stress is a powerful determinant of drug seeking in individuals with SUDs. This is problematic for relapse prevention, as stress is prevalent and unavoidable in the daily lives of drug addicts. Although the general idea that stress contributes to drug seeking is well established $\underline{22}, \underline{23}, \underline{24}$, the nature of this contribution appears to be more complex than previously thought. While it is true that in some cases, stress can serve as a direct 
trigger for drug craving $2, \underline{11}$, supported by findings in rodent models $\underline{\underline{11})}$, recent evidence points to a more opportunistic role of stress that involves interactions with other factors that promote relapse [e.g., cues, drug re-exposure; $\underline{4}, \underline{5}, \underline{25}$ ]. Consistent with reports from individuals with SUDs, these findings imply that stress may function by augmenting the ability of other stimuli to elicit drug seeking, thereby "setting the stage" for relapse. We have recently established a preclinical model for these stage-setting effects of stress wherein stress can potentiate, but not directly trigger, reinstatement of cocaine seeking in response to an otherwise subthreshold priming injection of cocaine $\underline{8}, \underline{10}$. Similarly, it has been reported that stress can potentiate the reinstatement of drug seeking upon the presentation of drug-associated cues $\underline{7}, \underline{9}, \underline{26}$. Importantly, evidence suggests that the neurobiological processes that mediate stress-potentiated reinstatement are distinct from those that mediate stress-triggered cocaine seeking. Specifically, shock-potentiated cocaine seeking, observed in rats with a history of shorter daily access to cocaine, requires acute elevation of corticosterone (8) and $C^{2} B_{1} R$ activation (10), while shock-triggered cocaine seeking, observed in rats with a history of longer daily access to cocaine, does not $\underline{10}, \underline{26}$.

Here we identify the prelimbic subregion of the medial prefrontal cortex as a critical site of action for the corticosterone-dependent stage-setting effects of stress on cocaine seeking. We demonstrate that the ability of stress and stress-level corticosterone to potentiate cocaine-induced reinstatement is reproduced by intra-PL corticosterone delivery. The PL has been previously implicated in drug seeking in response to multiple reinstating stimuli $\underline{13}, \underline{14}, \underline{15}$ and is critical for the control of goal-directed behavior (27). Moreover, the medial prefrontal cortex is highly responsive to stress, as it contains a high density of glucocorticoid $\underline{\text { receptors }} \underline{28}, \underline{29}$ and is heavily regulated by corticosterone, which acts in the region to exert negative feedback on the hypothalamic-pituitary-adrenal axis $18, \underline{30}$ and modify neuronal morphology $\underline{31}, \underline{32}$, gene $\underline{\text { transcription } 33}, \underline{34}$, synaptic physiology $\underline{18}, \underline{35}, \underline{36}, \underline{37}, \underline{38}$, and behavior $\underline{39}, \underline{40}, \underline{41}, \underline{42}$.

In the $\mathrm{PL}$, corticosterone likely regulates cocaine seeking through a $\mathrm{CB}_{1} \mathrm{R}$-dependent attenuation of GABAergic neurotransmission. Here we report that both stress- and corticosterone-potentiated reinstatement are prevented by intra-PL administration of the $C_{1} R$ antagonist $\underline{A M 251}$, while intra-PL administration of the $C_{B} R$ agonist WIN 55,212-2 is sufficient to potentiate cocaine-induced reinstatement. The $P L C B_{1} R$ s are located predominately on GABAergic interneurons $(18)$ and activation of $\mathrm{CB}_{1} \mathrm{Rs}$ in the prefrontal cortex attenuates inhibitory neurotransmission (43). In mice, ex vivo bath application of corticosterone to medial prefrontal cortex slices produces a $\mathrm{CB}_{1} \mathrm{R}$-dependent reduction in inhibitory neurotransmission (18). Furthermore, we demonstrate that bath application of corticosterone to rat PL slices attenuates both spontaneous and evoked inhibitory neurotransmission via a $\mathrm{CB}_{1} \mathrm{R}$-dependent presynaptic mechanism in rats.

The effects of stress and corticosterone on reinstatement likely involve mobilization of 2-AG in the PL. Prior studies have suggested that stress and glucocorticoids mobilize $2-A G \underline{44}, \underline{45}$, particularly in the prefrontal cortex (18). Here we report that intra-PL delivery of a monoacylglycerol lipase inhibitor, URB602, which elevates 2-AG brain content $\underline{46}, \underline{47}$, is sufficient to potentiate reinstatement in response to low-dose cocaine, similar to what is observed with stress, corticosterone, and intra- $P L C_{1} R$ agonist administration. However, a role for anandamide signaling was not examined in the current study and cannot be ruled out. To determine if corticosterone potentiates reinstatement through 2-AG mobilization, we utilized a novel DAGL inhibitor, DO34, which reduces 2-AG brain content (48). Bath application of DO34 blocks depolarization-induced suppression of inhibition in the PL, which is known to be $\mathrm{CB}_{1} \mathrm{R}$ dependent (18), suggesting that mobilization of 2-AG is critical for endocannabinoid-regulated synaptic plasticity, while intra-PL DO34 both prevents corticosterone-potentiated reinstatement and reduces PL 2-AG content in corticosterone-treated rats without altering anandamide levels. Interestingly, while intra-PL administration of the DAGL inhibitor DO34 reduced 2-AG content in corticosteronetreated rats, a corticosterone-induced elevation of PL 2-AG was not observed, in contrast to earlier studies demonstrating glucocorticoid-dependent stress-induced mobilization of 2-AG (16). However, these findings are 
consistent with reports that systemic administration of corticosterone alone does not elevate anandamide or 2AG in the prefrontal cortex as observed with bulk tissue dissection (49). Given that a majority of brain tissue 2AG content is not involved in signaling (50), tissue concentration of 2-AG may not be sensitive to an increase in 2-AG mobilization at the synapse. The mechanism through which corticosterone regulates $\mathrm{PL}$ endocannabinoid signaling is unclear and will require further investigation.

Our data suggest that corticosterone potentiates reinstatement through an endocannabinoid-mediated, likely 2AG, attenuation of inhibitory neurotransmission, which should increase the excitability of outputs mediating drug seeking. This is supported by findings that acute stress recruits endocannabinoid signaling, specifically 2$A G$, to attenuate inhibitory neurotransmission in the basolateral amygdala (44). While the current study did not directly examine specific PL projection fields, the projection pathway from the PL to the nucleus accumbens core is one likely to be affected as it has been established as a key pathway for cocaine

seeking $\underline{13}, \underline{14}, \underline{15}, \underline{51}, \underline{52}, \underline{53}$. Specifically, we hypothesize that corticosterone mobilizes 2 -AG, thereby activating $\mathrm{CB}_{1} \mathrm{Rs}$ that regulate GABA release from cortical interneurons, to attenuate inhibitory regulation of corticoaccumbens pyramidal projection neurons. This disinhibition would render the cortico-accumbens pathway more responsive to convergent PL excitatory inputs, including those activated by stimuli that trigger cocaine seeking. This hypothesis is consistent with a previous report that attenuated GABAergic neurotransmission in the medial prefrontal cortex facilitates cue-induced reinstatement to nicotine seeking (54). However, this requires further study, as it is unknown whether corticosterone-potentiated reinstatement results in increased activation of the cortico-accumbens pathway, and there are several possible PL projection pathways that can regulate potentiated cocaine seeking. Furthermore, while $\mathrm{CB}_{1} \mathrm{Rs}$ are predominantly on $\mathrm{GABAergic}$ terminals in the $\mathrm{PL}$, it is not currently known whether corticosterone can potentially regulate neurotransmission in a $C B_{1} R$-dependent manner through non-GABAergic mechanisms.

While our findings demonstrate that the PL is an important site for corticosterone effects, it is not the only site at which corticosterone can regulate cocaine seeking. This may contribute to the differential magnitude of reinstatement observed with intraperitoneal versus intra-PL administration of corticosterone. We previously reported that corticosterone delivery into the nucleus accumbens can also potentiate cocaine-induced reinstatement in rats. However, the effects of corticosterone in the nucleus accumbens involve its inhibition of organic cation transporter 3, a secondary uptake mechanism for monoamines, and the resulting decrease in dopamine clearance (8). However, there is likely interplay between the two brain regions, and others, during reinstatement. Furthermore, it is possible that organic cation transporter 3 and endocannabinoid mechanisms may work in tandem within the PL itself. Ultimately, the ability of corticosterone to regulate behavior at multiple sites suggests that during periods of stress, glucocorticoids may impose a brain state that produces system-wide changes in synaptic transmission to promote adaptive behavioral response patterns. The ubiquitous nature of endocannabinoid signaling suggests that glucocorticoid mobilization of 2-AG may serve as a key mechanism through which stress shifts neuronal excitabilityand therefore influence behavior at the network level.

The complexity of the contribution of stress to drug seeking has limited our ability to develop effective strategies for relapse prevention aimed at targeting stress-responsive mechanisms. Here we report that stress, under conditions in which it does not directly trigger responding, can potentiate cocaine-induced reinstatement in a rodent model, thereby setting the stage for cocaine seeking. This approach is consistent with many clinical reports and therefore may offer greater validity for studying the contribution of stress to relapse. Importantly, the observation that the neurobiological mechanisms underlying these "stage-setting" effects of stress are distinct from those through which stress triggers cocaine seeking, suggests that this model has the potential to reveal new targets for relapse prevention.

Finally, while our findings have direct implications for understanding SUDs, the ability of stress to modify synaptic transmission and neuronal excitability in the PL via glucocorticoid regulation of endocannabinoid 
signaling has important implications for a range of stress-related pathological conditions that have been associated with prefrontal cortical dysregulation.

\section{Acknowledgments and Disclosures}

This work was supported by National Institutes of Health Grant Nos. DA015758 (to JRM), DA038663 (to JRM, CJH, Q-SL), and DA035217 (to Q-SL).

JRM and DAB are consultants for and stakeholders in Promentis Pharmaceuticals Inc. CJH is on the Scientific Advisory Board for Phytecs, Inc. The other authors report no biomedical financial interests or potential conflicts of interest.

\section{References}

$\underline{1}$ R. Sinha, Y. Shaham, M. Heilig Translational and reverse translational research on the role of stress in drug craving and relapse Psychopharmacology (Berl), 218 (2011), pp. 69-82

$\underline{2}$ R. Sinha Modeling stress and drug craving in the laboratory: Implications for addiction treatment development Addict Biol, 14 (2009), pp. 84-98

$\underline{3}$ K.L. Preston, D.H. Epstein Stress in the daily lives of cocaine and heroin users: Relationship to mood, craving, relapse triggers, and cocaine use Psychopharmacology (Berl), 218 (2011), pp. 29-37

4 M. Furnari, D.H. Epstein, K.A. Phillips, M.L. Jobes, W.J.Kowalczyk, M. Vahabzadeh, et al. Some of the people, some of the time: Field evidence for associations and dissociations between stress and drug use Psychopharmacology (Berl), 232 (2015), pp. 3529-3537

$\underline{5}$ K. Preston, M. Vahabzadeh, J. Schmittner, J.-L. Lin, D.Gorelick, D. Epstein Cocaine craving and use during daily life Psychopharmacology (Berl), 207 (2009), pp. 291-301

6 M.M. Moran-Santa Maria, A. McRae-Clark, N.L. Baker, V.Ramakrishnan, K.T. Brady Yohimbine administration and cue-reactivity in cocaine-dependent individuals Psychopharmacology (Berl), 231 (2014), pp. 41574165

$\underline{7}$ M.W. Feltenstein, R.E. See Potentiation of cue-induced reinstatement of cocaine-seeking in rats by the anxiogenic drug yohimbine Behav Brain Res, 174 (2006), pp. 1-8

8 E.N. Graf, R.A. Wheeler, D.A. Baker, A.L. Ebben, J.E. Hill, J.R. McReynolds, et al. Corticosterone acts in the nucleus accumbens to enhance dopamine signaling and potentiate reinstatement of cocaine seeking J Neurosci, 33 (2013), pp. 11800-11810

9 D.M. Buffalari, R.E. See Footshock stress potentiates cue-induced cocaine-seeking in an animal model of relapse Physiol Behav, 98 (2009), pp. 614-617

10 J.R. McReynolds, E.M. Doncheck, O. Vranjkovic, G.S.Ganzman, D.A. Baker, C.J. Hillard, J.R. Mantsch CB1 receptor antagonism blocks stress-potentiated reinstatement of cocaine seeking in rats Psychopharmacology (Berl), 233 (2016), pp. 99-109

11 J.R. Mantsch, D.A. Baker, D. Funk, A.D. Lê, Y. Shaham Stress-induced reinstatement of drug seeking: 20 Years of progress Neuropsychopharmacology, 41 (2016), pp. 335-356

12 Y. Shaham, U. Shalev, L. Lu, H. De Wit, J. Stewart The reinstatement model of drug relapse: History, methodology and major findings Psychopharmacology (Berl), 168 (2003), pp. 3-20

$\underline{13} \mathrm{~K}$. McFarland, P.W. Kalivas The circuitry mediating cocaine-induced reinstatement of drug-seeking behavior J Neurosci, 21 (2001), pp. 8655-8663

14 K. McFarland, S. Davidge, C. Lapish, P. Kalivas Limbic and motor circuitry underlying footshock-induced reinstatement of cocaine-seeking behavior J Neurosci, 24 (2004), pp. 1551-1560

15 M.T. Stefanik, K. Moussawi, Y.M. Kupchik, K.C. Smith, R.L. Miller, M.L. Huff, et al. Optogenetic inhibition of cocaine seeking in rats Addict Biol, 18 (2013), pp. 50-53 
16 M. Popoli, Z. Yan, B.S. McEwen, G. Sanacora The stressed synapse: The impact of stress and glucocorticoids on glutamate transmission Nat Rev Neurosci, 13 (2011), pp. 22-37

17 J.M. McKlveen, B. Myers, J.P. Herman The medial prefrontal cortex: Coordinator of autonomic, neuroendocrine and behavioural responses to stress J Neuroendocrinol, 27 (2015), pp. 446-456

18 M.N. Hill, R.J. McLaughlin, B. Pan, M.L. Fitzgerald, C.J.Roberts, T.T. Lee, et al. Recruitment of prefrontal cortical endocannabinoid signaling by glucocorticoids contributes to termination of the stress response J Neurosci, 31 (2011), pp. 10506-10515

19 T.J. De Vries, Y. Shaham, J.R. Homberg, H. Crombag, K.Schuurman, J. Dieben, et al. A cannabinoid mechanism in relapse to cocaine seeking Nat Med, 7 (2001), pp. 1151-1154

20 D.A. Kupferschmidt, P.G. Klas, S. Erb Cannabinoid CB1 receptors mediate the effects of corticotropinreleasing factor on the reinstatement of cocaine seeking and expression of cocaine-induced behavioural sensitization $\mathrm{Br}$ J Pharmacol, 167 (2012), pp. 196-206

21 B. Pan, C.J. Hillard, Q.S. Liu D2 dopamine receptor activation facilitates endocannabinoid-mediated longterm synaptic depression of GABAergic synaptic transmission in midbrain dopamine neurons via CAMP-protein kinase A signaling J Neurosci, 28 (2008), pp. 14018-14030

$\underline{22}$ R. Sinha Chronic stress, drug use, and vulnerability to addiction Ann N Y Acad Sci, 1141 (2008), pp. 105-130

$\underline{23}$ R. Sinha, H.C. Fox, K.-I.A.I. Hong, J. Hansen, K. Tuit, M.J.Kreek Effects of adrenal sensitivity, stress- and cueinduced craving, and anxiety on subsequent alcohol relapse and treatment outcomes Arch Gen Psychiatry, 68 (2011), pp. 942-952

$\underline{24}$ R. Sinha New findings on biological factors predicting addiction relapse vulnerability Curr Psychiatry Rep, 13 (2011), pp. 398-405

25 P.S. Regier, Z.A. Monge, T.R. Franklin, R.R. Wetherill, A.Teitelman, K. Jagannathan, et al. Emotional, physical and sexual abuse are associated with a heightened limbic response to cocaine cues Addict Biol, 22 (2017), pp. 1768-1777

$\underline{26}$ K.M. Banna, S.E. Back, P. Do, R.E. See Yohimbine stress potentiates conditioned cue-induced reinstatement of heroin-seeking in rats Behav Brain Res, 208 (2010), pp. 144-148

27 S.L. Gourley, J.R. Taylor Going and stopping: Dichotomies in behavioral control by the prefrontal cortex Nat Neurosci, 19 (2016), pp. 656-664

28 M.J. Meaney, R.M. Sapolsky, D.H. Aitken, B.S. McEwen [3H]dexamethasone binding in the limbic brain of the fetal rat Brain Res, 355 (1985), pp. 297-300

29 J.M. Reul, E.R. de Kloet Two receptor systems for corticosterone in rat brain: Microdistribution and differential occupation Endocrinology, 117 (1985), pp. 2505-2511

30 D. Diorio, V. Viau, M.J. Meaney The role of the medial prefrontal cortex (cingulate gyrus) in the regulation of hypothalamic-pituitary-adrenal responses to stress J Neurosci, 13 (1993), pp. 3839-3847

31 C.L. Wellman Dendritic reorganization in pyramidal neurons in medial prefrontal cortex after chronic corticosterone administration J Neurobiol, 49 (2001), pp. 245-253

32R.M. Anderson, R.M. Glanz, S.B. Johnson, M.M. Miller, S.A. Romig-Martin, J.J. Radley Prolonged corticosterone exposure induces dendritic spine remodeling and attrition in the rat medial prefrontal cortex J Comp Neurol, 524 (2016), pp. 3729-3746

33 J.D. Mikkelsen, M.H. Larsen Effects of stress and adrenalectomy on activity-regulated cytoskeleton protein (Arc) gene expression Neurosci Lett, 403 (2006), pp. 239-243

34 J.R. McReynolds, C.M. Holloway-Erickson, T.U. Parmar, C.K. McIntyre Corticosterone-induced enhancement of memory and synaptic Arc protein in the medial prefrontal cortex Neurobiol Learn Mem, 112 (2014), pp. 148-157

35 R.-J.J. Liu, G.K. Aghajanian Stress blunts serotonin- and hypocretin-evoked EPSCs in prefrontal cortex: Role of corticosterone-mediated apical dendritic atrophy Proc Natl Acad Sci U S A, 105 (2008), pp. 359-364 
36 E.Y. Yuen, J. Wei, W. Liu, P. Zhong, X. Li, Z. Yan Repeated stress causes cognitive impairment by suppressing glutamate receptor expression and function in prefrontal cortex Neuron, 73 (2012), pp. 962-977

37 L. Musazzi, M. Milanese, P. Farisello, S. Zappettini, D.Tardito, V.S. Barbiero, et al. Acute stress increases depolarization-evoked glutamate release in the rat prefrontal/frontal cortex: The dampening action of antidepressants PLoS One, 5 (2010), p. e8566

38 G. Treccani, L. Musazzi, C. Perego, M. Milanese, N. Nava, T. Bonifacino, et al. Stress and corticosterone increase the readily releasable pool of glutamate vesicles in synaptic terminals of prefrontal and frontal cortex Mol Psychiatry, 19 (2014), pp. 433-443

39 B. Roozendaal, J.R. McReynolds, J.L. McGaugh The basolateral amygdala interacts with the medial prefrontal cortex in regulating glucocorticoid effects on working memory impairment J Neurosci, 24 (2004), pp. 1385-1392

40 C. Liston, M.M. Miller, D.S. Goldwater, J.J. Radley, A.B.Rocher, P.R. Hof, et al. Stress-induced alterations in prefrontal cortical dendritic morphology predict selective impairments in perceptual attentional setshifting J Neurosci, 26 (2006), pp. 7870-7874

$\underline{41}$ E.Y. Yuen, W. Liu, I.N. Karatsoreos, J. Feng, B.S. McEwen, Z. Yan Acute stress enhances glutamatergic transmission in prefrontal cortex and facilitates working memory Proc Natl Acad Sci U S A, 106 (2009), pp. 14075-14079

$\underline{42}$ S. Koot, M. Koukou, A. Baars, P. Hesseling, J. van 't Klooster, M. Joëls, R. van den Bos Corticosterone and decision-making in male Wistar rats: The effect of corticosterone application in the infralimbic and orbitofrontal cortex Front Behav Neurosci, 8 (2014), p. 127

43 C.Q. Chiu, N. Puente, P. Grandes, P.E. Castillo Dopaminergic modulation of endocannabinoid-mediated plasticity at GABAergic synapses in the prefrontal cortex J Neurosci, 30 (2010), pp. 7236-7248

44 S. Di, C.A. Itoga, M.O. Fisher, J. Solomonow, E.A. Roltsch, N.W. Gilpin, J.G. Tasker Acute stress suppresses synaptic inhibition and increases anxiety via endocannabinoid release in the basolateral amygdala J Neurosci, 36 (2016), pp. 8461-8470

45 S. Di, R. Malcher-Lopes, K.C. Halmos, J.G. Tasker Nongenomic glucocorticoid inhibition via endocannabinoid release in the hypothalamus: A fast feedback mechanism J Neurosci, 23 (2003), pp. 4850-4857

46 A.R. King, A. Duranti, A. Tontini, S. Rivara, A. Rosengarth, J.R. Clapper, et al .URB602 inhibits monoacylglycerol lipase and selectively blocks 2-arachidonoylglycerol degradation in intact brain slices Chem Biol, 14 (2007), pp. 1357-1365

47 J. Wiskerke, C. Irimia, B.F. Cravatt, T.J. De Vries, A.N.Schoffelmeer, T. Pattij, L.H. Parsons Characterization of the effects of reuptake and hydrolysis inhibition on interstitial endocannabinoid levels in the brain: An in vivo microdialysis study ACS Chem Neurosci, 3 (2012), pp. 407-417

48 D. Ogasawara, H. Deng, A. Viader, M.P. Baggelaar, A.Breman, H. den Dulk, et al. Rapid and profound rewiring of brain lipid signaling networks by acute diacylglycerol lipase inhibition Proc Natl Acad Sci U S A, 113 (2016), pp. 26-33

49 M.N. Hill, I.N. Karatsoreos, C.J. Hillard, B.S. McEwen Rapid elevations in limbic endocannabinoid content by glucocorticoid hormones in vivo Psychoneuroendocrinology, 35 (2010), pp. 1333-1338

50 M.W. Buczynski, L.H. Parsons Quantification of brain endocannabinoid levels: Methods, interpretations and pitfalls Br J Pharmacol, 160 (2010), pp. 423-442

51 K. McFarland, C. Lapish, P. Kalivas Prefrontal glutamate release into the core of the nucleus accumbens mediates cocaine-induced reinstatement of drug-seeking behavior I Neurosci Official J Soc Neurosci, 23 (2003), pp. 3531-3537

52 M.T. Stefanik, Y.M. Kupchik, P.W. Kalivas Optogenetic inhibition of cortical afferents in the nucleus accumbens simultaneously prevents cue-induced transient synaptic potentiation and cocaine-seeking behavior Brain Struct Funct, 221 (2016), pp. 1681-1689 
53 E.M. McGlinchey, M.H. James, S.V. Mahler, C. Pantazis, G.Aston-Jones Prelimbic to accumbens core pathway is recruited in a dopamine-dependent manner to drive cued reinstatement of cocaine seeking J Neurosci, 36 (2016), pp. 8700-8711

54 B.R. Lubbers, Y. van Mourik, D. Schetters, A.B. Smit, T.J.De Vries, S. Spijker Prefrontal gamma-aminobutyric acid type $A$ receptor insertion controls cue-induced relapse to nicotine seeking Biol Psychiatry, 76 (2014), pp. 750-758

(C) 2017 Society of Biological Psychiatry.

\section{Supplementary Material}

\section{Stress Promotes Drug Seeking Through Glucocorticoid-Dependent Endocannabinoid Mobilization in Prelimbic Cortex}

\section{Supplemental Information}

\section{Supplemental Methods and Materials}

Subjects: Male Sprague-Dawley rats (275-300g at arrival) obtained from Envigo (Indianapolis, IN) were individually housed in a humidity- and temperature-controlled, AAALAC-accredited facility with ad libitum access to food and water. Rats were housed under a 12-h/12-h reverse light/dark cycle (0700-1900 lights off). For electrophysiology experiments, male Sprague-Dawley rats (200-250g at arrival) were obtained from Charles River laboratories (Wilmington, MA). All behavioral procedures were completed in the dark phase of the light cycle. All experimental procedures were carried out in compliance with National Institutes of Health Guidelines and were approved by Institutional Animal Care and Use Committees (Marquette University and Medical College of Wisconsin).

Surgery: For intravenous cocaine self-administration, rats were anesthetized with ketamine $\mathrm{HCl}(100 \mathrm{mg} / \mathrm{kg}$, i.p.; Henry Schein, Melville, NY) and xylazine ( $2 \mathrm{mg} / \mathrm{kg}$, i.p.; Henry Schein, Melville, NY) and had an indwelling venous catheter implanted surgically. The polyurethane ( $0.6 \mathrm{~mm}$ i.d. x $1.1 \mathrm{~mm}$ o.d.; Access Technologies, Skokie, IL) catheters were connected to a back-mounted cannula (Plastics One, Roanoke, VA) attached to polypropylene mesh (500 microns; Small Parts, Logansport, IN). Catheters were implanted into the superior vena cava with the back-mount placement situated approximately 1 inch behind the scapula. For rats that received intra-prelimbic cortical (PL) infusions prior to reinstatement testing, guide cannula were surgically implanted immediately following catheter surgery. For guide cannula implantation, the skull was positioned $\mathrm{n}$ a stereotaxic frame (Stoelting Inc; Wood Dale, IL) and two 11-mm stainless steel guide cannula (26 gauge; Plastics One, Roanoke, VA) were positioned $0.5 \mathrm{~mm}$ above the $\mathrm{PL}$ [coordinates (in $\mathrm{mm}$ ): anteroposterior (A/P): +2.8 from Bregma; mediolateral $(\mathrm{M} / \mathrm{L}):+1.0$ from midline; dorsoventral $(\mathrm{D} / \mathrm{V})$ : -3.5 from the skull surface; incisor bar: -3.3 from interaural line (Paxinos and Watson, 2005)]. Guide cannula were fixed in place with acrylic dental cement and four small anchoring screws. Internal dummy cannula were inserted into each cannula to maintain patency. Rats were given Bio-Serv Rimadyl tablets ( 5 g; Fisher Scientific; Hampton, $\mathrm{NH}$ ) in their cage for 3 days and antibiotic treatment $(100 \mathrm{mg} / \mathrm{kg}$, iv; Cefazolin; Henry Schein, Melville, NY) for at least 5 days following surgery. All rats recovered for a minimum of one week before the initiation of self-administration.

Cocaine self-administration, extinction, and reinstatement: Self-administration procedures were conducted in computer-interfaced operant conditioning chambers equipped with retractable levers and stimulus lights above 
each lever in sound-attenuating cubicles (MED-Associates; Fairfax, VT). Following recovery from surgery, rats were food deprived to $90 \%$ of their body weight and were then trained to receive sucrose pellets by pressing a lever under a fixed-ratio (FR) 1 schedule. Once rats successfully acquired lever pressing for food, rats were then switched over to self- administer cocaine $(0.5 \mathrm{mg} / \mathrm{kg} /$ infusion) by pressing a lever under a FR1 schedule during daily 2 - $\mathrm{h}$ sessions. Pressing the lever resulted in an infusion ( $200 \mu \mathrm{L}$ over 5 -sec) followed by a 10-sec time-out period, during which lever presses were recorded but not reinforced and the stimulus light above the lever was extinguished and the house light turned on. Responding on a second, inactive lever was also recorded but not reinforced. Following stable responding, the FR value was increased gradually to FR4. Once stable responding on FR4 was maintained ( $<10 \%$ change over 3 days), rats were provided access to cocaine for self-administration during daily 2-h sessions for 14 days. Rats then underwent extinction training, wherein the cocaine syringe was replaced with saline, until the extinction criterion was met ( $<10$ lever presses $/ 2 \mathrm{~h}$ ). Once rats met this criterion, a reinstatement test was conducted the following day.

Reinstatement conditions: The 2 -h reinstatement tests were preceded by footshock, corticosterone, and cocaine and/or drug delivery but were otherwise identical to extinction conditions. A complete within-subjects design was used wherein all rats underwent multiple reinstatement tests within each experiment in a counterbalanced fashion for a maximum of 6 reinstatement tests. Rats that did not complete all reinstatement tests were excluded from analysis. Rats were given additional extinction/washout sessions between reinstatement tests to reestablish extinction criterion ( $<10$ lever presses $/ 2 \mathrm{~h}$ ) before receiving additional tests. For stress-potentiated reinstatement of cocaine seeking, the electric footshock stress $(3 \times 0.5 \mathrm{~mA}, 200$-msec duration, mean intershock interval 40-sec, range 10-70-sec over a 15-min period) was administered through stainless steel grid floors. Immediately following cessation of the electric footshock stress, a subthreshold dose of cocaine ( $2.5 \mathrm{mg} / \mathrm{kg}$, i.p.) or saline was given followed by the 2-h reinstatement session. For corticosterone- potentiated reinstatement of cocaine seeking, a systemic injection of corticosterone $(2 \mathrm{mg} / \mathrm{kg}$, i.p) or vehicle $(10 \% \mathrm{EtOH})$ was administered $40-$ min prior to an injection of low-dose cocaine $(2.5 \mathrm{mg} / \mathrm{kg}$, i.p) or saline, followed by the 2 -h reinstatement session.

Intra-cranial drug administration: HBC-conjugated corticosterone (50 ng/0.3 $\mu \mathrm{L}$; Sigma-Aldrich, St. Louis, MO), the CB1R antagonist AM251 (300 ng/0.3 $\mu \mathrm{L}$; Sigma-Aldrich, St. Louis, MO), the CB1R agonist WIN 55,212-2 (50 $\mathrm{ng} / 0.3 \mu \mathrm{L}$; Sigma-Aldrich, St. Louis, MO), the MAGL inhibitor URB602 (300 pmol/0.3 $\mu \mathrm{L}$; Tocris, Bristol UK), or the DAGL inhibitor DO34 (0.1, $1.0 \mu \mathrm{g} / 0.3 \mu \mathrm{L}$; Cravatt Lab, Scripps Research Institute) were micro-infused directly into the PL at various times prior to reinstatement testing as described in the Results section. Infusion needles were comprised of $11.5 \mathrm{~mm}$ 30-gauge stainless steel injectors (Plastics One, Roanoke, VA) attached to polyethylene20 tubing and Hamilton syringes. The vehicle or drug was backfilled into the infusion needle and all drugs were infused at a volume of $0.3 \mu \mathrm{L}$ and at a rate of $0.3 \mu \mathrm{L} / \mathrm{min}$ using a syringe pump. The needles remained in place for an additional 1-min to allow for diffusion.

Trunk blood collection and plasma corticosterone analysis: To confirm that the systemic dose of corticosterone used in the study recapitulates stress-evoked increases in blood levels of corticosterone, plasma corticosterone levels were quantified by radioimmunoassay (RIA) following either electric footshock stress or systemic corticosterone administration. Some rats received the same 15-min intermittent electric footshock stress parameters used for behavioral testing, and were sacrificed immediately after cessation of the footshock. Other rats were assigned to a No Shock control wherein rats were placed in the self-administration chamber for 15 min and were sacrificed immediately afterward. Another group of rats were given a systemic injection of corticosterone $(2 \mathrm{mg} / \mathrm{kg}$, i.p.) or vehicle $(10 \% \mathrm{EtOH})$ and were sacrificed $40-\mathrm{min}$ after the injection. All animals were sacrificed by rapid decapitation, and trunk blood collected for analysis. Trunk blood was collected into centrifuge tubes containing heparin and the blood was spun in a centrifuge at $1000 \mathrm{xg}$ for 10 -min to separate the plasma. The plasma was transferred into a new tube and stored at $-80^{\circ} \mathrm{C}$ for long-term storage. 
Corticosterone levels in plasma were determined by using a 3H-Corticosterone RIA kit (MP Biomedicals, Santa Ana, CA) according to the manufacturer protocol.

Slice electrophysiology: Drug-naïve rats were anaesthetized by isoflurane inhalation and decapitated. Cortical slices were cut using a vibrating slicer (Leica, Wetzler, Germany). The slices were transferred into artificial cerebrospinal fluid (ACSF) containing (in $\mathrm{mM}$ ): $119 \mathrm{NaCl}, 2.5 \mathrm{KCl}, 2.5 \mathrm{CaCl} 2,1 \mathrm{MgCl} 2,1.25 \mathrm{NaH} 2 \mathrm{PO}$, $26 \mathrm{NaHCO}$, and 10 glucose, and allowed to recover at least one hour at room temperature. All solutions were saturated with 95\% $\mathrm{O} 2$ and 5\% CO2. Whole-cell voltage clamp recordings were made using a patch clamp amplifier (Multiclamp 700B; Molecular Devices, Sunnyvale, CA) under infrared-differential contrast interference microscopy. Data acquisition and analysis were performed using a digitizer (DigiData 1440A; Molecular Devices, Sunnyvale, CA) and analysis software pClamp 10 (Molecular Devices, Sunnyvale, CA). Pyramidal neurons in layer V of the PL were identified visually based upon pyramidal-shaped soma with a prominent apical dendrite. Additionally, the pyramidal neurons exhibit spike frequency adaptation in response to depolarizing current injections (1). For recording of evoked IPSCs, layer V pyramidal neurons were voltage-clamped at $-60 \mathrm{mV}$, and IPSCs were evoked at $0.05 \mathrm{~Hz}$ by a tungsten stimulation electrode placed near the apical dendrites. The pipettes were filled with an internal solution containing (in mM): $80 \mathrm{~K}$-gluconate, $60 \mathrm{KCl}, 10 \mathrm{HEPES}, 0.2 \mathrm{EGTA}, 2 \mathrm{MgCl} 2,2 \mathrm{Mg}-\mathrm{ATP}, 0.3$ $\mathrm{Na2GTP}$, and $10 \mathrm{Na2}$-phosphocreatine (pH 7.2 with $\mathrm{KOH})$. Spontaneous miniature IPSCs (mIPSCs) were recorded from pyramidal neurons at a holding potential of $-70 \mathrm{mV}$. Action potential generation was blocked with tetrodotoxin (TTX; $0.5 \mu \mathrm{M}$ ). Glutamate receptor antagonists 6-cyano-7-nitroquinoxaline-2,3-dione (CNQX, 10 $\mu \mathrm{M})$ and D-2-amino-5-phosphonovaleric acid (D-AP-5, $20 \mu \mathrm{M})$ were present in the ACSF throughout the experiments. Series resistance (15-30 M 2 ) was monitored throughout the recordings, and data were discarded if the resistance changed by more than $20 \%$. All recordings were performed at $32 \pm 1^{\circ} \mathrm{C}$ by using an automatic temperature controller.

Mass spectrometry: To assess effects of the DAGL inhibitor DO34 on corticosterone-induced 2arachidonoylglycerol (2-AG) content, rats received intra-PL infusions of DO34 $(1 \mu \mathrm{g} / 0.3 \mu \mathrm{L})$ or vehicle $(70 \%$ DMSO) 30 min prior to a corticosterone $(2 \mathrm{mg} / \mathrm{kg}$, ip) or vehicle $(10 \% \mathrm{EtOH})$ injection. Rats were rapidly decapitated 45-min following the injection and brains were removed and flash frozen by submersion in liquid nitrogen (total time from decapitation was approximately $90-\mathrm{sec}$ ) and stored at $-80^{\circ} \mathrm{C}$. For tissue dissection, 1 $\mathrm{mm}$ prelimbic prefrontal cortical sections (approx. $3.72 \mathrm{~mm}$ to $-2.76 \mathrm{~mm}$ from Bregma) were isolated from coronal sections on dry ice as described previously (2) and stored at $-80^{\circ} \mathrm{C}$. Placement of guide cannula was visually confirmed to be in the prelimbic cortex during dissection. Tissue samples were weighed and homogenized in acetonitrile containing $67 \mathrm{pmol}\left[{ }^{2} \mathrm{H} 8\right] \mathrm{AEA}$ and $8 \mathrm{nmol}\left[{ }^{2} \mathrm{H} 8\right] 2-\mathrm{AG}$ (Cayman Chemical Company, Ann Arbor, MI), sonicated for $60 \mathrm{~min}$, and frozen overnight at $-20^{\circ} \mathrm{C}$ to precipitate proteins. Particulates were then removed by centrifugation at $1500 \times g$ for 2 minutes at $4^{\circ} \mathrm{C}$, after which the supernatant was rapidly extracted and concentrated under N2 gas re-suspended in 100\% methanol and AEA and 2-AG were isolated and quantified by tandem liquid chromatography-mass spectrometry (LC/MS/MS; Agilent Technologies 6460 Triple Quad LC/MS), and concentrations were calculated by isotope dilution as previously described (3).

Histology: To determine the accuracy of guide cannula placements, rats were sacrificed and brains were postfixed in $4 \%$ paraformaldehyde, cryoprotected in $30 \%$ sucrose, and finally $50 \mu \mathrm{m}$ sections were taken from the level of the prelimbic cortex using a cryostat. Tissue sections were mounted onto gelatin-coated slides and stained using a cresyl violet nuclear stain. Guide cannula placement was determined to be accurate if the injection needle terminated in the prelimbic region of the medial prefrontal cortex. A limited number of rats $(n=5)$ did not have bilateral hits for cannula placement and were excluded from the study. In each case, drug effects were not observed in rats that had injections outside of the prelimbic cortex.

Drugs: Cocaine $\mathrm{HCl}$ was obtained from the National Institute on Drug Abuse (NIDA) through the NIDA Drug Supply Program. Cocaine was dissolved in saline (0.9\% bacteriostatic saline). Corticosterone (Steroloids, 
Newport, RI) was dissolved in a $10 \% \mathrm{EtOH}$ in saline solution, and 2- hydroxypropyl- $\beta$-cyclodextrin (HBC)conjugated corticosterone (Sigma-Aldrich, St. Louis, MO) was dissolved in saline. AM251 (Sigma-Aldrich, St. Louis, MO), WIN-55,212 (Tocris, Bristol, UK), URB502 (Tocris, Bristol, UK), and DO34 (0.1 $\mu \mathrm{g}$ ) were made in a vehicle containing 10\% DMSO in saline. DO34 $(1 \mu \mathrm{g})$ was made in a vehicle containing $70 \%$ DMSO in saline.

Statistical analysis: Statistical analyses were conducted using SPSS (IBM Analytics, Armonk, NY) or Sigmaplot (Systat Software, San Jose, CA) statistics software. For behavioral experiments, lever responding was analyzed using two-way repeated measures ANOVA followed by post-hoc testing using Bonferroni-corrected t-tests. For electrophysiology experiments, IPSC amplitude was normalized to the baseline. The depression (\%) of IPSCs by corticosterone was calculated as follows: $100 \times$ [mean amplitude of IPSCs during the last 5 min treatment/mean amplitude of baseline IPSCs]. Data sets were compared with Student's $t$-test. For mass spectrometry, endocannabinoid content was analyzed using a two-way ANOVA followed by post-hoc testing. For all analyses, statistical significance was defined as $p<.05$.

\section{Supplemental Data}

Table S1. Cocaine self-administration and extinction responding. Data represent total active lever responses/2-h session for Figures 1, 3, 4 and 5 during days 1 and 14 of cocaine self-administration (SA) and total active lever responses/2-h session on the first day of extinction (Ext) and the last day of extinction before reinstatement testing for experiments 1 and 2 . The number of days to reach extinction criteria for each experiment is also reported. Data are represented as mean \pm SEM. (EFS, Electric footshock stress; COC, cocaine; CORT, corticosterone; PL, prelimbic cortex; AM251, CB1R antagonist; WIN, WIN 55,212-2 CB1R agonist; URB602, monoacylglycerol lipase inhibitor; D034; diacylglycerol lipase inhibitor).

\begin{tabular}{|l|l|l|l|l|l|l|}
\hline & Cocaine SA & & Extinction & & $\begin{array}{l}\text { Range of } \\
\text { Days to Ext }\end{array}$ & $\begin{array}{l}\text { Average Days } \\
\text { to Ext }\end{array}$ \\
\hline $\begin{array}{l}\text { Experiment no. } \\
\text { (n) }\end{array}$ & SA Day 1 & SA Day 14 & First Ext & Last Ext & \# Days & \# Days \\
\hline $\mathbf{1}$ EFS/COC; (6) & $\begin{array}{l}106.00 \pm \\
8.10\end{array}$ & $\begin{array}{l}123.83 \pm \\
7.48\end{array}$ & $\begin{array}{l}68.50 \pm \\
13.57\end{array}$ & $\begin{array}{l}8.67 \pm \\
1.43\end{array}$ & $5-10$ & $8.00 \pm 0.85$ \\
\hline $\mathbf{1}$ CORT/COC; (5) & $121.40 \pm$ & $\begin{array}{l}114.00 \pm \\
10.18\end{array}$ & $\begin{array}{l}33.2 \pm \\
13.57\end{array}$ & $\begin{array}{l}13.35 \\
1.80 \pm\end{array}$ & $5-15$ & $8.80 \pm 1.69$ \\
\hline $\mathbf{1}$ PL CORT/ & $115.86 \pm$ & $137.71 \pm$ & $68.85 \pm$ & $7.57 \pm$ & $5-17$ & $8.28 \pm 1.76$ \\
COC; (7) & 10.98 & 24.25 & 7.53 & 1.57 & & \\
\hline 3 PL AM251/ & $123.67 \pm$ & $128.33 \pm$ & $76.00 \pm$ & $7.17 \pm$ & $4-12$ & $7.17 \pm 1.19$ \\
EFS/COC; (6) & 8.38 & 6.95 & 19.24 & 1.49 & & \\
\hline 3 PL AM251/ & $131.00 \pm$ & $132.50 \pm$ & $71.83 \pm$ & $8.83 \pm$ & $5-20$ & $8.83 \pm 2.30$ \\
CORT/COC; (6) & 15.18 & 14.32 & 12.59 & 1.54 & & \\
\hline 4 PL WIN/ & $146.33 \pm$ & $149.50 \pm$ & $68.50 \pm$ & $5.17 \pm$ & $5-9$ & $6.67 \pm 0.56$ \\
COC; (6) & 17.95 & 28.00 & 10.13 & 2.52 & & \\
\hline 4 PL URB602/ & $112.67 \pm$ & $117.33 \pm$ & $77.67 \pm$ & $8.17 \pm$ & $3-9$ & $6.17 \pm 0.98$ \\
COC (6) & 8.46 & 6.45 & 15.08 & 1.72 & & \\
\hline 5 PL DO34/ & $112.60 \pm$ & $122.60 \pm$ & $32.00 \pm$ & $5.00 \pm$ & $5-13$ & $9.00 \pm 1.52$ \\
CORT/COC (5) & 11.44 & 18.99 & 12.41 & 1.58 & & \\
\hline
\end{tabular}

Table S2. Detailed statistics for experiments depicted in Figure 1. Two-way repeated measures (RM) ANOVAs were conducted with reinstatement condition and day (extinction, reinstatement) as factors. These were followed by separate one-way RM ANOVAs examining responding during extinction and reinstatement testing. 
Post-hoc testing was conducted using Bonferroni-corrected t- tests. ${ }^{*}$ denotes significance. (Ext=extinction; Rst=reinstatement; Coc=cocaine, Cort=corticosterone; Sal=saline; Veh=vehicle).

\begin{tabular}{|c|c|c|c|}
\hline Figure $1 \mathrm{~A}$ & & & \\
\hline 2-way RM ANOVA & & Post hoc test: Ext vs Rst & \\
\hline Condition & $F(3,15)=18.05, p<.001^{*}$ & No Shock/Sal & $p>.05$ \\
\hline Day & $F(1,5)=29.59, p<.01 *$ & Shock/Sal & $p>.05$ \\
\hline \multirow[t]{2}{*}{ Condition X Day } & $F(3,15)=17.11, p<.001^{*}$ & No Shock/Coc & $p<.05^{*}$ \\
\hline & & Shock/Coc & $\mathrm{p}<.01 *$ \\
\hline 1-way RM ANOVA & & $\begin{array}{l}\text { Post hoc test: Rst - } \\
\text { Shock/Coc vs }\end{array}$ & \\
\hline Extinction & $F(3,15)=.05, p>.05$ & No Shock/Sal & $p=.06$ \\
\hline \multirow[t]{2}{*}{ Reinstatement } & $F(3,15)=19.26, p<.001^{*}$ & Shock/Sal & $\mathrm{p}<.05^{*}$ \\
\hline & & No Shock/Coc & $p<.05^{*}$ \\
\hline \multicolumn{4}{|l|}{ Figure $1 \mathrm{~B}$} \\
\hline 2-way RM ANOVA & & Post hoc test: Ext vs Rst & \\
\hline Condition & $F(3,12)=7.38, p<.01^{*}$ & Veh/Sal & $p>.05$ \\
\hline Day & $F(1,4)=5.50, p=.07$ & Cort/Sal & $p>.05$ \\
\hline \multirow[t]{2}{*}{ Condition X Day } & $F(3,12)=10.30, p<.001^{*}$ & Veh/Coc & $p>.05$ \\
\hline & & Cort/Coc & $\mathrm{p}<.05^{*}$ \\
\hline 1-way RM ANOVA & & $\begin{array}{l}\text { Post hoc test: Rst - } \\
\text { Cort/Coc vs }\end{array}$ & \\
\hline Extinction & $F(3,12)=.55, p>.05$ & Veh/Sal & $p>.05$ \\
\hline \multirow[t]{2}{*}{ Reinstatement } & $F(3,12)=9.07, p<.01^{*}$ & Cort/Sal & $p>.05$ \\
\hline & & Veh/Coc & $p>.05$ \\
\hline \multicolumn{4}{|l|}{ Figure 1C } \\
\hline 2-way RM ANOVA & & Post hoc test: Ext vs Rst & \\
\hline Condition & $F(2,12)=3.99, p<.05^{*}$ & Cort/Sal & $p>.05$ \\
\hline Day & $F(1,6)=6.78, p<.05^{*}$ & Veh/Coc & $p>.05$ \\
\hline Condition X Day & $F(2,12)=4.89, p<.05^{*}$ & Cort/Coc & $p<.05^{*}$ \\
\hline 1-way RM ANOVA & & $\begin{array}{l}\text { Post hoc test: Rst - } \\
\text { Cort/Coc vs }\end{array}$ & \\
\hline Extinction & $F(2,12)=1.01, p>.05$ & Cort/Sal & $p>.05$ \\
\hline Reinstatement & $F(2,12)=4.80, p<.05^{*}$ & Veh/Coc & $p>.05$ \\
\hline
\end{tabular}

Table S3. Detailed statistics for experiments depicted in Figure 3. Two-way repeated measures (RM) ANOVAs were conducted with reinstatement condition and day (extinction, reinstatement) as factors. These were followed by separate one-way RM ANOVAs examining responding during extinction and reinstatement testing. Post-hoc testing was conducted using Bonferroni-corrected t- tests. * denotes significance. (Ext=extinction; Rst=reinstatement; Coc=cocaine, Cort=corticosterone; Sal=saline; Veh=vehicle).

\begin{tabular}{|l|l|l|l|}
\hline Figure 3A & & & \\
\hline 2-way RM ANOVA & & Post hoc test: Ext vs Rst & \\
\hline Condition & $\mathrm{F}(3,15)=10.64, \mathrm{p}<.001^{*}$ & Veh/Shock/Sal & $\mathrm{p}>.05$ \\
\hline Day & $\mathrm{F}(1,5)=8.80, \mathrm{p}<.05^{*}$ & Veh/No Shock/Coc & $\mathrm{p}>.05$ \\
\hline Condition X Day & $\mathrm{F}(3,15)=15.71, \mathrm{p}<.001^{*}$ & Veh/Shock/Coc & $\mathrm{p}<.01^{*}$ \\
\hline & & AM251/Shock/Coc & $\mathrm{p}>05$ \\
\hline 1-way RM ANOVA & & $\begin{array}{l}\text { Post hoc test: } \text { Rst }- \\
\text { Veh/Shock/Coc vs }\end{array}$ & \\
\hline Extinction & Veh/Shock/Sal & $\mathrm{p}<.05^{*}$ \\
\hline
\end{tabular}




\begin{tabular}{|l|l|l|l|}
\hline Reinstatement & $\mathrm{F}(3,15)=19.26, \mathrm{p}<.001^{*}$ & Veh/No Shock/Coc & $\mathrm{p}<.05^{*}$ \\
\hline & & AM251/Shock/Coc & $\mathrm{p}=.06$ \\
\hline Figure 3B & & & \\
\hline 2-way RM ANOVA & & Post hoc test: Ext vs Rst & \\
\hline Condition & $\mathrm{F}(3,15)=9.52, \mathrm{p}<.001^{*}$ & Veh/Cort/Sal & $\mathrm{p}>.05$ \\
\hline Day & $\mathrm{F}(1,5)=11.14, \mathrm{p}<.05^{*}$ & Veh/Veh/Coc & $\mathrm{p}>.05$ \\
\hline Condition X Day & $\mathrm{F}(3,15)=6.94, \mathrm{p}<.01^{*}$ & Veh/Cort/Coc & $\mathrm{p}<.05^{*}$ \\
\hline & & AM251/Cort/Coc & $\mathrm{p}>.05$ \\
\hline 1-way RM ANOVA & & $\begin{array}{l}\text { Post hoc test: Rst }- \\
\text { Veh/Cort/Coc vs }\end{array}$ & \\
\hline Extinction & & Veh/Cort/Sal & $\mathrm{p}>.05$ \\
\hline Reinstatement & $\mathrm{F}(3,15)=1.41, \mathrm{p}>.05$ & Veh/Veh/Coc & $\mathrm{p}>.05$ \\
\hline & $\mathrm{F}(3,15)=14.39, \mathrm{p}<.001^{*}$ & AM251/Cort/Coc & $\mathrm{p}>.05$ \\
\hline
\end{tabular}

Table S4. Detailed statistics for experiments depicted in Figure 4. Two-way repeated measures (RM) ANOVAs were conducted with reinstatement condition and day (extinction, reinstatement) as factors. These were followed by separate one-way RM ANOVAs examining responding during extinction and reinstatement testing. Post-hoc testing was conducted using Bonferroni-corrected t- tests. * denotes significance. (Ext=extinction; Rst=reinstatement; Coc=cocaine; Sal=saline; Veh=vehicle; WIN=WIN 55,212-2).

\begin{tabular}{|l|l|l|l|}
\hline Figure 4A & & & \\
\hline 2-way RM ANOVA & & Post hoc test: Ext vs Rst & \\
\hline Condition & $\mathrm{F}(2,10)=4.01, \mathrm{p}<.05^{*}$ & WIN/Sal & $\mathrm{p}>.05$ \\
\hline Day & $\mathrm{F}(1,5)=6.24, \mathrm{p}<.05^{*}$ & Veh/Coc & $\mathrm{p}>.05$ \\
\hline Condition X Day & $\mathrm{F}(2,10)=7.09, \mathrm{p}<.01^{*}$ & WIN/Coc & $\mathrm{p}<.05^{*}$ \\
\hline 1-way RM ANOVA & & Post hoc test: Rst - WIN/Coc vs & \\
\hline Extinction & $\mathrm{F}(2,10)=0.18, \mathrm{p}>.05$ & WIN/Sal & $\mathrm{p}>.05$ \\
\hline Reinstatement & $\mathrm{F}(2,10)=5.39, \mathrm{p}<.05^{*}$ & Veh/Coc & $\mathrm{p}>.05$ \\
\hline Figure 4B & & & \\
\hline 2-way RM ANOVA & & Post hoc test: Ext vs Rst & \\
\hline Condition & $\mathrm{F}(2,10)=5.26, \mathrm{p}<.05^{*}$ & URB602/Sal & $\mathrm{p}>.05$ \\
\hline Day & $\mathrm{F}(1,5)=8.12, \mathrm{p}<.05^{*}$ & Veh/Coc & $\mathrm{p}>.05$ \\
\hline Condition X Day & $\mathrm{F}(2,10)=5.89, \mathrm{p}<.05^{*}$ & URB602/Coc & $\mathrm{p}<.05^{*}$ \\
\hline 1-way RM ANOVA & & $\begin{array}{l}\text { Post hoc test: Rst }- \text { URB602/Coc } \\
\text { Vs }\end{array}$ & \\
\hline Extinction & & URB602/Sal & $\mathrm{p}>.05$ \\
\hline Reinstatement & $\mathrm{F}(2,10)=2.94, \mathrm{p}>.05$ & Veh/Coc & $\mathrm{P}<.01^{*}$ \\
\hline
\end{tabular}

Table S5. Detailed statistics for experiments depicted in Figure 5. Two-way repeated measures (RM) ANOVAs were conducted with reinstatement condition and day (extinction, reinstatement) as factors. These were followed by separate one-way RM ANOVAs examining responding during extinction and reinstatement testing. Post-hoc testing was conducted using Bonferroni-corrected t- tests. * denotes significance. (Ext=extinction; Rst=reinstatement; Coc=cocaine; Sal=saline; Veh=vehicle; DO=DO34).

\begin{tabular}{|l|l|l|l|}
\hline Figure 5C & & & \\
\hline 2-way RM ANOVA & & Post hoc test: Ext vs Rst & \\
\hline Condition & $\mathrm{F}(4,16)=5.28, \mathrm{p}<.01^{*}$ & Veh/Cort/Sal & $\mathrm{p}>.05$ \\
\hline Day & $\mathrm{F}(1,4)=7.24, \mathrm{p}<.05^{*}$ & Veh/Veh/Coc & $\mathrm{p}>.05$ \\
\hline Condition X Day & $\mathrm{F}(3,16)=3.84, \mathrm{p}<.05^{*}$ & Veh/Cort/Coc & $\mathrm{p}<.05^{*}$ \\
\hline
\end{tabular}




\begin{tabular}{|l|l|l|l|}
\hline & & DO(0.1)/Cort/Coc & $\mathrm{p}>.05$ \\
\hline 1-way RM ANOVA & & DO(1.0)/Cort/Coc & $\mathrm{p}>.05$ \\
\hline Extinction & $\begin{array}{l}\text { Post hoc test: Rst }- \\
\text { Veh/Cort/Coc vs }\end{array}$ & \\
\hline Reinstatement & $\mathrm{F}(4,16)=2.11, \mathrm{p}>.05$ & Veh/Cort/Sal & $\mathrm{p}>.05$ \\
\hline & $\mathrm{F}(4,16)=4.62, \mathrm{p}<.01^{*}$ & Veh/Veh/Coc & $\mathrm{p}>05$ \\
\hline & & $\mathrm{DO}(0.1) /$ Cort/Coc & $\mathrm{p}>.05$ \\
\hline & & $\mathrm{DO}(1.0) /$ Cort/Coc & $\mathrm{p}>.05$ \\
\hline
\end{tabular}

Supplemental Figure S1. Plasma levels of corticosterone following footshock or systemic corticosterone administration. A) Timeline of blood collection. Time points were selected to correspond to the start of the reinstatement session in rats tested for behavior. B) 15-min of electric footshock stress (Shock) significantly increases plasma levels of corticosterone $(n=7-8, * * p<.01$ compared to No Shock). Systemic administration of corticosterone ( $n=5-11,2 \mathrm{mg} / \mathrm{kg}$, i.p.) significantly increases plasma levels of corticosterone similar to levels observed with footshock ( ${ }^{* *} p<.01$, compared to Vehicle). Data are represented as mean \pm SEM.
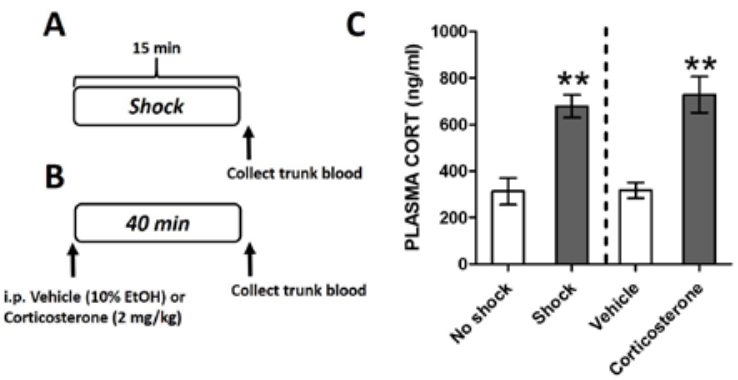

Supplementary Figure S2. Direct administration of the diacylglycerol lipase inhibitor DO34 $(1 \mu \mathrm{g} / 0.3 \mu \mathrm{L})$ into the prelimbic cortex (PL) 30-min prior to a systemic injection of corticosterone (CORT; $2 \mathrm{mg} / \mathrm{kg}$, i.p) has no effect on $P L$ anandamide (AEA) content ( $n=7-8, p>.05)$.

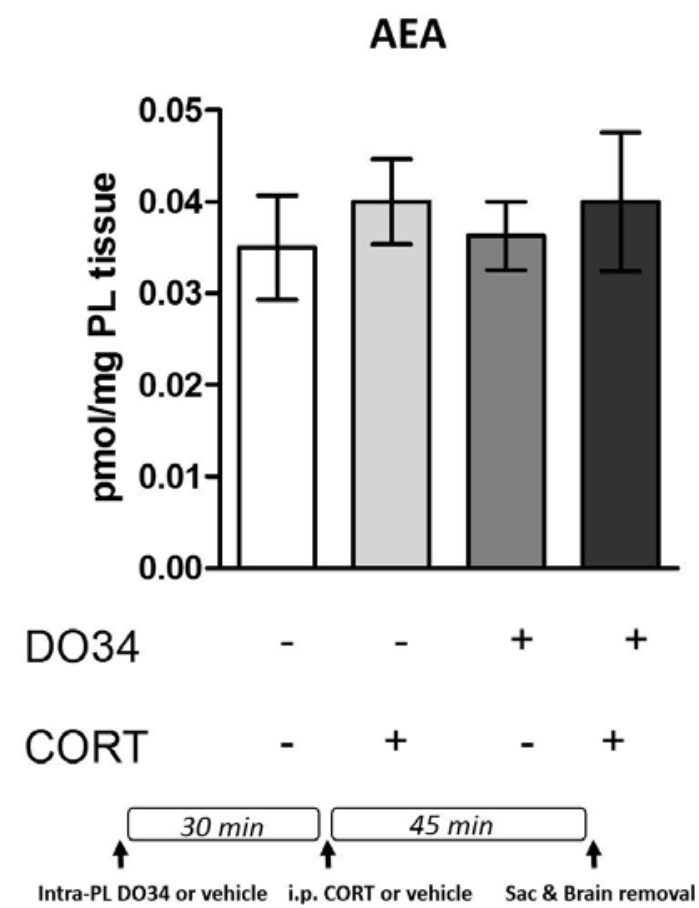


Supplementary Figure S3. Inactive lever responding during extinction and reinstatement tests. There was no significant effect of reinstatement condition on lever responding under any condition. A) Inactive lever responding corresponding to Fig 1 A. B) Inactive lever responding corresponding to Fig 1B. C) Inactive lever responding corresponding to Fig $1 \mathrm{C}$. D) Inactive lever responding corresponding to Fig $3 \mathrm{~A}$. E) Inactive lever responding corresponding to Fig 3B. F) Inactive lever responding corresponding to Fig 4A. G) Inactive lever responding corresponding to Fig 4B. H) Inactive lever responding corresponding to Fig 5C. (COC, cocaine; CORT, corticosterone; PL, prelimbic cortex; AM251, CB1R antagonist; WIN, WIN 55,212-2 CB1R agonist; URB602, monoacylglycerol lipase inhibitor; DO34; diacylglycerol lipase inhibitor).

\section{Supplemental References}

1. Satake T, Mitani H, Nakagome K, Kaneko K (2008): Individual and additive effects of neuromodulators on the slow components of afterhyperpolarization currents in layer $\mathrm{V}$ pyramidal cells of the rat medial prefrontal cortex. Brain Res 1229: 47-60.

2. McReynolds JR, Doncheck EM, Vranjkovic O, Ganzman GS, Baker DA, Hillard CJ, Mantsch JR (2016): CB1 receptor antagonism blocks stress-potentiated reinstatement of cocaine seeking in rats. Psychopharmacology (Berl) 233: 99-109.

3. Spagnolo PA, Ramchandani VA, Schwandt ML, Kwako LE, George DT, Mayo LM, et al. (2016): FAAH Gene Variation Moderates Stress Response and Symptom Severity in Patients with Posttraumatic Stress Disorder and Comorbid Alcohol Dependence. Alcohol Clin Exp Res 40: 